\title{
miR-27a-3p regulates the inhibitory influence of endothelin 3 on the tumorigenesis of papillary thyroid cancer cells
}

\author{
HONGXIN CHEN $^{1}$, BINLIN CAI $^{1}, \mathrm{KUN} \mathrm{LIU}^{1}$ and QINGQUAN HUA ${ }^{2}$ \\ ${ }^{1}$ Department of Otorhinolaryngology-Head and Neck Surgery, Wuhan Puren Hospital, \\ Wuhan, Hubei 430081; ${ }^{2}$ Department of Otorhinolaryngology-Head and Neck Surgery, \\ Wuhan University Renmin Hospital, Wuhan, Hubei 430060, P.R. China
}

Received April 29, 2020; Accepted January 4, 2021

DOI: $10.3892 / \mathrm{mmr} .2021 .11882$

\begin{abstract}
Several studies on papillary thyroid cancer (PTC) have been performed. However, the effects of endothelin 3 (EDN3) and microRNA (miR)-27a-3p on PTC cells has yet to be investigated, to the best of the authors' knowledge. The present study aimed to explore the biological functions of EDN3 and miR-27a-3p in PTC cells. Bioinformatics analysis was conducted to identify possible key genes and miRs involved in PTC progression. Western blot analysis and reverse transcription-quantitative (RT-q) PCR were employed to confirm the key genes or miRs expressed in PTC cells. Cytological methods were used to detect cell viability, proliferation, apoptosis and migration and luciferase reporter assay was performed to confirm the relationship between END3 and miR-27a-3p. After analyzing the results of gene microarray analyses and RT-qPCR, EDN3 with low expression was identified as the key gene associated with PTC progression. It was also found that EDN3 overexpression in PTC cells impaired cell viability, proliferation and migration but promoted cell apoptosis. In addition, the findings revealed that miR-27a-3p could relieve the inhibitory influence of EDN3 on PTC cells by binding to EDN3 mRNA 3' untranslated region (UTR), thereby suppressing EDN3 expression. Overall, the results of the present study demonstrated that by binding to EDN3 mRNA 3'UTR, miR-27a-3p could attenuate the inhibitory function of EDN3 in the tumorigenesis of PTC cells.
\end{abstract}

\section{Introduction}

Thyroid carcinoma is the most prevalent type of neck carcinoma in the world and the various forms of thyroid carcinoma include papillary thyroid cancer (PTC), medullary thyroid

Correspondence to: Dr Qingquan Hua, Department of Otorhinolaryngology-Head and Neck Surgery, Wuhan University Renmin Hospital, 238 Jiefang Road, Wuhan, Hubei 430060, P.R. China

E-mail: hqq15072@163.com

Key words: miR-27a-3p, endothelin 3, papillary thyroid cancer cancer and anaplastic thyroid cancer $(1,2)$. Among them, PTC is the commonest type of thyroid carcinoma and it accounts for $\sim 90 \%$ of thyroid carcinoma cases (3). According to the National Cancer Institute, the most frequently used PTC treatments include surgery (thyroidectomy or lobectomy), radioactive iodine therapy and hormone therapy to prevent the body from making thyroid-stimulating hormone (4). Although patients with PTC have impressive survival outcomes, some patients with PTC remain vulnerable to the risk of recurrence due to the aggressive nature of PTC $(5,6)$. Therefore, clinicians and researchers still need to investigate the molecular mechanisms of this type of cancer to improve the recurrence-free survival rate.

Endothelin (EDN) 3 is a protein that belongs to the EDN family, which consists of vasoactive peptides (EDN1, EDN2 and EDN3) that are widely expressed in the brain, pancreas, colon, small intestine and skeletal muscle of humans $(7,8)$. A number of studies have demonstrated that this protein, found in humans, participates in cell proliferation, migration and differentiation by interacting with the cell surface receptors [including EDN receptor A (EDNRA) and EDN receptor B (EDNRB)] through an autocrine mechanism (9-13). EDN1 can directly affect tumor cells by stimulating cell proliferation, migration and invasion and inhibiting cell apoptosis $(14,15)$. The overexpression of EDN1 in PTC has also been reported (16-18). Unlike EDN1, EDN3 has been only recently been found to be frequently downregulated or silenced in human tumors $(19,20)$. Studies have documented the ability of EDN3 to promote hypermethylation in breast cancer (21) and colon carcinoma (20). EDN3 knockdown has also been reported to impair tumor-sphere formation, cell spreading and cell migration of glioblastoma stem cells (22). Although Qiu et al (23) found in their bioinformatical analysis that the downregulation of EDN3 was associated with the PTC stage, the exact role of EDN3 in PTC cells remains to be elucidated. Using bioinformatics analysis, the present study identified EDN3 as a potentially critical participant in PTC in terms of regulating cell development, migration and proliferation.

In recent years, miRs have been reported to be critical to the development of human cancers (24-28). By binding to the 3' untranslated region (UTR) of the target mRNA, these small non-coding RNA molecules can impede mRNA transcription (29-31). Previous studies have documented that 
miR-27a-3p, a member of the miR-27a family, can suppress or enhance cancer development depending on the types of human cancers. While miR-27a-3p acts as a tumor suppressor in non-small cell lung carcinoma (32) and hepatocellular carcinoma (33), it functions as a tumor promoter in gastric cancer (34), colorectal cancer (35), ovarian carcinoma (36) and esophageal carcinoma (37). In addition, miR-27a is demonstrated to upregulate and promote cell migration in thyroid cancer (38).

The object of the present study was to identify the key genes and miRs in PTC cells using bioinformatics methods and to explore the influence of the key genes and miRs on PTC cells using in vitro cytological techniques. It was hypothesized that EDN3 and miR-27a-3p could be promising biomarkers for PTC treatments.

\section{Materials and methods}

Microarray data analysis. For analysis, two mRNA expression profiles, GSE33630 and GSE3678, were downloaded from the NCBI GEO database (https://www.ncbi.nlm.nih.gov/geo/). GSE33630 consisted of 45 normal thyroid tissue samples and 49 PTC tissue samples, while GSE3678 comprised 7 normal thyroid tissue samples and 7 PTC tissue samples. The downregulated differentially expressed genes (DEGs) were identified using the R software version 3.2.3 (https://www.r-project.org/) and limma $\mathrm{R}$ package version 3.26 .8 with adjusted $\mathrm{P}<0.05$ and $\log$ fold change $(\log \mathrm{FC})<-1$. The downregulated DEGs were then uploaded to the STRING database version 10.5 (https://string-db.org/) to perform Gene Ontology and Kyoto Encyclopedia of Genes and Genomes enrichment analysis. To confirm the key miRs, GSE113629 was downloaded from the NCBI GEO database, including 5 normal thyroid tissue samples and 5 PTC tissue samples. The significantly overexpressed miRs were identified using the limma $\mathrm{R}$ package with adjusted $\mathrm{P}<0.05$ and $\log \mathrm{FC}>1$. TarBase version 7.0 (http://carolina.imis.athena-innovation.gr/diana tools/web/index.php? $\mathrm{r}=$ tarbasev8/index) and TargetScan version 7.1 (http://www.targetscan.org/vert_71/) were the online tools used to predict the binding site between $\mathrm{miR}$ and mRNA 3'UTR.

The collection of clinical specimens. A total of 30 PTC tumor tissues and 30 non-tumor tissues were collected from Wuhan Puren Hospital (China). The present study was approved by the Ethics Committee of Wuhan Puren Hospital (approval no. A01401-LL201912-002). All clinical specimens were stored in liquid nitrogen until experiments. The clinical characteristics of patients with PTC are demonstrated in Table I.

Cell culture. TPC-1, GLAG-66 cell lines (human PTC cell lines) and Nthy-ori 3-1 cell line (human thyroid cell line transformed by simian virus 40) were provided by the Chinese Academic of Sciences (China) and were cultured in DMEM media (HyClone; Cytiva). Another human PTC cell line (CUTC5), obtained from the University of Colorado Cancer Center Tissue Culture Shared Resource, was kept in RPMI 1640 media (HyClone; Cytiva). The DMEM and RPMI 1640 media were supplemented with $2 \mathrm{mM}$ L-glutamine (Gibco; Thermo Fisher Scientific, Inc.) and 10\% fetal bovine serum
(FBS, Gibco; Thermo Fisher Scientific, Inc.). All the cells were cultured at $37^{\circ} \mathrm{C}$ in an atmosphere containing $5 \% \mathrm{CO}_{2}$. The fresh medium was replaced every $24 \mathrm{~h}$ during the cell culture.

$m R N A$ preparation and reverse transcription-quantitative $(R T-q)$ PCR. The total RNAs from PTC tissues, non-tumor tissues and Nthy-ori 3-1, TPC-1, CUTC5 and GLAG-66 cells $\left(1 \times 10^{6}\right.$ cells $/ \mathrm{ml}$ ) were extracted using TRIzol ${ }^{\circledR}$ (Thermo Fisher Scientific, Inc.) according to the manufacturer's protocols. Chloroform was then added to prepare the samples for centrifugation at $1,2000 \mathrm{xg}\left(15 \mathrm{~min}, 4^{\circ} \mathrm{C}\right)$. Subsequently, $500 \mu 175 \%$ ethanol was added to the supernatant to further purify all the RNAs. Following purification, the RNA purity and concentration were assessed by determining the spectrophotometric absorbance of the samples at 230, 260 and $280 \mathrm{~nm}$ as well as the ratios of A260:A280 and A260:A230. The PrimeScript RT Reagent kit and SYBR Premix Ex Taq II kit, obtained from Takara Bio, Inc., were used to synthesize cDNA (20 $\mu 1$ reaction volume; thermocycling: $37^{\circ} \mathrm{C}$ for $15 \mathrm{~min}$ followed by $85^{\circ} \mathrm{C}$ for $5 \mathrm{sec}$ ) and perform fluorescence RT-qPCR, respectively, according to the manufacturer's protocols. The Fluorescent Quantitative PCR System (Applied Biosystems; Thermo Fisher Scientific, Inc.) was employed to measure gene expression with the following reaction conditions: $95^{\circ} \mathrm{C}$ for $30 \mathrm{sec}, 40$ cycles at $95^{\circ} \mathrm{C}$ for $3 \mathrm{sec}$ followed by $60^{\circ} \mathrm{C}$ for $30 \mathrm{sec}$. All the primers for RT-qPCR were synthesized by and purchased from Takara Bio, Inc. The primer sequences used in the present study are presented in Table II. The expression of mRNA was normalized with $\beta$-actin miR expression and the expression of miR was normalized with U6 expression. The experiments were repeated three times. The $2^{-\Delta \Delta C q}$ method was used to calculate the relative mRNA expression (39).

Western blotting. The total protein from the pretreated cells was lysed in RIPA reagent (Beyotime Institute of Biotechnology) with $10 \mathrm{mM}$ Tris-HCl, $1 \%$ NP-40 and protease inhibitors. The supernatant containing the proteins was centrifuged for $20 \mathrm{~min}$ at $12,000 \mathrm{x} \mathrm{g}$ at $4^{\circ} \mathrm{C}$. The $\mathrm{BCA}$ Protein Assay kit (Beyotime Institute of Biotechnology) was applied to detect the concentration of isolated protein. All the proteins $(20 \mu \mathrm{g})$ were isolated with $12 \%$ SDS-PAGE. The solution was transferred onto PVDF membranes (Membrane Solutions). Following blocking with $5 \%$ non-fat milk at $25^{\circ} \mathrm{C}$ for $2 \mathrm{~h}$, the membranes were incubated with the primary antibodies against EDN3 (1:1,000; cat. no. ab96709; Abcam) and $\beta$-actin $(1: 1,000$; cat. no. ab8224; Abcam) overnight at $4^{\circ} \mathrm{C}$. The following day, the membranes were incubated with corresponding secondary antibodies (1:5,000; Rabbit antibody cat. no. ab6721; Mouse antibody cat. no. ab6789; Abcam) for 3 h. The Enhanced Chemiluminescence Reagent (Thermo Fisher Scientific, Inc.) was used to enhance the signals of protein bands. The densitometry of bands was analyzed by ImageJ version 1.8.0 (National Institutes of Health).

Plasmid construction and cell transfection. The EDN3 overexpression (EDN3-OE) plasmid was constructed by cloning the full-length of EDN3 into the pcDNA3.1 vector (Shanghai GeneChem Co., Ltd.). HinDI and BamHI restriction sites were used. Briefly, the primers used to get the cloned portion of EDN3 were forward (5'-TCTAGGTTCATGGAGCCGGG-3') and 
Table I. Correlation of the expression of miR-27a-3p and EDN3 with clinicopathologic features.

\begin{tabular}{|c|c|c|c|c|c|c|}
\hline & \multicolumn{2}{|c|}{$\begin{array}{c}\text { miR-27a-3p } \\
\text { expression }\end{array}$} & \multirow[b]{2}{*}{ P-value ${ }^{a}$} & \multicolumn{2}{|c|}{$\begin{array}{c}\text { EDN3 } \\
\text { expression }\end{array}$} & \multirow[b]{2}{*}{ P-value } \\
\hline & High & Low & & High & Low & \\
\hline Age (years) & & & 0.264 & & & 0.710 \\
\hline$>45$ & 7 & 11 & & 8 & 10 & \\
\hline$\leq 45$ & 8 & 4 & & 7 & 5 & \\
\hline Sex & & & 0.450 & & & 1 \\
\hline Male & 7 & 4 & & 5 & 6 & \\
\hline Female & 8 & 11 & & 10 & 9 & \\
\hline Tumor diameter $(\mathrm{cm})$ & & & 0.107 & & & 0.014 \\
\hline$>2$ & 7 & 2 & & 1 & 8 & \\
\hline$\leq 2$ & 8 & 13 & & 14 & 7 & \\
\hline TNM stage & & & 0.027 & & & 0.003 \\
\hline $\mathrm{I}+\mathrm{II}$ & 4 & 11 & & 12 & 3 & \\
\hline II+IV & 11 & 4 & & 3 & 12 & \\
\hline
\end{tabular}

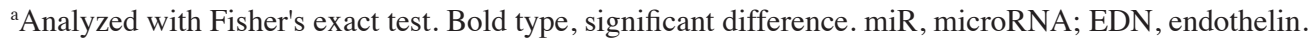

Table II. The primer sequences for reverse transcriptionquantitative PCR.

\begin{tabular}{ll}
\hline Gene & \multicolumn{1}{c}{ Primer sequences $\left(5^{\prime} \rightarrow 3^{\prime}\right)$} \\
\hline miR- & Forward: CGCGTTCACAGTGGCTAAGT \\
27a-3p & Reverse: GTGCAGGGTCCGAGGTATTC \\
U6 & Forward: CTCGCTTCGGCAGCACA \\
& Reverse: AACGCTTCACGAATTTGCGT \\
EDN3 & Forward: GCGCTCTGAAAGTTCGTGAC \\
& Reverse: ACAGCTTTCGAGTCCTGTCG \\
CXCL12 & Forward: AGAGCCAACGTCAAGCATCT \\
& Reverse: TAATTTCGGGTCAATGCACA \\
3-actin & Forward: GGAGATTACTGCCCTGGCTCCTAGC \\
& Reverse: GGCCGGACTCATCGTACTCCTGCTT
\end{tabular}

reverse (5'-CACCGTCTGTTCGGGAGT-3'). The product was subjected to double digestion with HinDI and BamHI enzymes (Takara Bio, Inc.). The digested DNA products were ligated into a 5.4-kb fragment of pcDNA3.1 (Shanghai GeneChem Co., Ltd.) that was digested with the same enzymes. The miR-27a-3p mimic (5'-UUCACAGUGGCUAAGUUCCGC-3') and non-targeting sequence (negative control, NC) plasmids were provided by Shanghai GenePharma Co., Ltd. $50 \mathrm{nM}$ EDN3-overexpression (OE) and/or miR-27a-3p mimic was transfected into the cells for $48 \mathrm{~h}$ using Lipofectamine ${ }^{\circledR} 3000$ Transfection Reagent (cat. no. L3000015; Invitrogen; Thermo Fisher Scientific, Inc.). The NC was transfected into the cells as the NC group. The transfection efficiency of EDN3-OE and/or miR-27a-3p mimic was evaluated using RT-qPCR. All subsequent experimentation was performed following transfection for $48 \mathrm{~h}$.
Cell viability assessment. The cell viability of transfected PTC cells was detected using the Cell Counting Kit-8 (CCK-8) reagent (Dojindo Molecular Technologies, Inc.). Then, 10,000 cells/well cells undergoing transfection were seeded in the 96-well plate and cultured for 0, 24, 48 and $72 \mathrm{~h}$. For each period, $10 \mu \mathrm{l} /$ well CCK- 8 reagents were added before the cells were incubated for $2 \mathrm{~h}$. The optical density (OD) was detected at $450 \mathrm{~nm}$ wavelength using a microplate reader (Dynex Technologies).

BrdU cell proliferation assay. The assay was performed with the BrdU Cell Proliferation ELISA kit (cat. no. ab126556, Abcam). Briefly, the TPC-1 and GLAG-66 cells were seeded in 96-well plates and transfected with EDN3-OE, miR-27a-3p mimic or NC plasmids. After $72 \mathrm{~h}$, the cells were treated with the BrdU Cell Proliferation ELISA kit according to the manufacturer's protocol. Then the OD value was detected at $450 \mathrm{~nm}$ using a microplate reader (Dynex Technologies).

Caspase-3 activity assessment. Since caspase-3 activity is enhanced during cell apoptosis, the cell apoptosis was determined using the caspase-3 Assay kit (cat. no. ab39401, Abcam). After transfecting the cells for $48 \mathrm{~h}, 1.5 \times 10^{6}$ cells were collected and re-suspended in $50 \mu \mathrm{l}$ chilled cell lysis buffer. The supernatant was then collected. The protein concentration was measured and adjusted to $1-4 \mu \mathrm{g} / \mu \mathrm{l}$. Next, the cell lysate was added to the $50 \mu \mathrm{l}$ reaction buffer mixed with $10 \mathrm{mM}$ dithiothreitol and $50 \mu$ l DEVD-p-NA substrate. The mixture was subsequently incubated for $2 \mathrm{~h}$. After the cell incubation process, the absorbance was measured at $405 \mathrm{~nm}$ using a microplate reader (Dynex Technologies).

Apoptosis analysis. The transformed cells were re-suspended at a density of $1 \times 10^{6}$ cells $/ \mathrm{ml}$. The apoptosis was detected using the Annexin V-APC Apoptosis Detection kit 
(eBioscience; Thermo Fisher Scientific, Inc.) according to the manufacturer's protocol. The detection and quantification of apoptotic cells were performed using a BD FACSCalibur flow cytometer (Becton, Dickinson and Company). The data were analyzed with FlowJo software version 7.6.1 (FlowJo LLC). The untreated and unstained cell lines served as the basis for gating. Finally, the samples were stained with sodium propionate iodide $(50 \mu \mathrm{g} / \mathrm{ml})$ solution in calcium buffer solution. The apoptotic rate was determined as the percentage of early + late apoptotic cells.

Cell migration detection. Wound healing assay was performed to evaluate cell migration. Transfected PTC cells $\left(1 \times 10^{5}\right)$ were cultured in the six-well plate in serum-containing medium until the cell density reached $\sim 80 \%$ confluence. Next, the serum medium was replaced with freshly new serum-free medium for $24 \mathrm{~h}$. A $2 \mathrm{~mm}$ width scratch was made with $200 \mu \mathrm{l}$ sterile plastic pipette tips on every cell monolayer. The cell debris was removed using PBS. The cell monolayers, which showed cells migrating into the wounds from five fields, were imaged using a light microscope (magnification, x100) at 0 and $24 \mathrm{~h}$. The migration rate was calculated as follows:

$$
\text { migration rate }=1-\frac{\text { wound width at indicating time point }}{\text { wound width at } 0 \mathrm{~h}}
$$

Transwell invasion assay. The invasiveness of TPC-1 and GLAG-66 cells was tested with 24-well Transwell cell culture chambers $(8.0 \mu \mathrm{m}$ pore size, polycarbonate membrane, Corning, Inc.). Subsequently, $1 \times 10^{5}$ cells were added to the upper chamber in $100 \mu \mathrm{l}$ serum-free medium. The lower chamber was filled with $0.6 \mathrm{ml}$ medium containing $10 \%$ FBS. Following incubation at $37^{\circ} \mathrm{C}$ in an atmosphere containing $5 \% \mathrm{CO}_{2}$ for $20 \mathrm{~h}$, the cells on the upper surface of the filter were removed by swabbing. The filter was fixed in $4 \%$ paraformaldehyde and stained with crystal violet at room temperature for $5 \mathrm{~min}$. Under the microscope (magnification, $\mathrm{x} 100$ ), five visual fields were randomly selected to count the stained cells using ImageJ version 1.8.0 (National Institutes of Health).

Luciferase reporter assay. The pGL4 luciferase reporter vectors inserted by wild-type EDN3 3'UTR (EDN3-WT) or mutated EDN3 3'UTR plasmids (EDN3-MUT) were purchased from Shanghai GenePharma Co., Ltd. The pGL4-EDN3-WT or pGL4-EDN3-MUT were co-transfected into TPC-1 and GLAG-66 cells together with miR-27a-3p mimic or NC. After $48 \mathrm{~h}$, the luciferase activity was detected with the Pierce Renilla-Firefly Luciferase Dual Assay kit (cat. no. 16185; Thermo Fisher Scientific, Inc.). The relative luciferase activity was normalized to Renilla luciferase activity.

Statistical analysis. All experimental data were presented in the form of mean \pm standard deviation from three independent experiments. GraphPad Prism 6 (GraphPad Software, Inc.) was utilized for statistical analysis. Student's t-test was used to compare the statistical difference between two groups, while one-way ANOVA with Dunnett's or Tukey's multiple comparisons test was employed to compare the statistical differences among multiple groups. Paired t-test was used to compare the gene expression in clinical tissues. For the analysis of the association between clinical characteristics and gene expression, Fisher's exact test was used. For the analysis of the correlation between gene expression levels, Spearman's analysis method was used. $\mathrm{P}<0.05$ was considered to indicate a statistically significant difference.

\section{Results}

EDN3 and miR-27a-3p, the potential key regulators in PTC. A gene microarray analysis of GSE33630 was carried out to identify 565 DEGs associated with PTC, with adjusted $\mathrm{P}<0.05$ and $\log \mathrm{FC}<-1$. To center on the more significant DEGs, another gene microarray analysis (GSE3678) was conducted and 364 DEGs were identified. A total of 257 DEGs overlapped (Fig. 1A). The 257 genes could potentially participate in PTC progression. After uploading the $257 \mathrm{DEGs}$ to the STRING database, C-X-C Motif Chemokine Ligand 12 (CXCL12) and EDN3 were discovered to be the interacting genes involved in cell development, cell migration and cell proliferation. This suggested that the CXCL12 and EDN3 might be the crucial regulators in PTC (Fig. 1B). The expression of these two genes in the collected tissue samples was detected using RT-qPCR. It was found that, compared with the expression in the normal tissue samples, the expression of EDN3 mRNA significantly declined, while no significantly difference was observed in the expression of CXCL12 mRNA (Fig. 1C). Based on this result, EDN3 was identified as the gene of interest in PTC. Subsequently, to identify a regulator miRNA of EDN3, TarBase and TargetScan databases were used to predict the potential complementary miRs of EDN3. Respectively, 5 and $490 \mathrm{miRs}$ were predicted by the two algorithms. In addition, a total of 2,314 over-expressed miRs in PTC was identified using limma $\mathrm{R}$ package analysis of a miR microarray (GSE113629). It was discovered that three miRs (hsa-miR-579-3p, hsa-miR-769-3p and hsa-miR-27a-3p) were the overlap of the three datasets. (Fig. 1D). A previous study reported that miR-27a can upregulate and promote the cancer phenotypes of PTC (37). Nonetheless, its experiments were only conducted in the IHH4 cell line; to expand on the role of miR-27a-3p, it was hypothesized that the relevance of the results should be confirmed with another PTC cell line. Moreover, the function of $\mathrm{miR}-27 \mathrm{a}-3 \mathrm{p}$ by regulating its downstream target in PTC has never been reported before, to the best of the authors' knowledge. Hence, EDN3 and miR-27a-3p were chosen as the key mRNA and miRNA to be further investigated in PTC.

The expression of EDN3 decreases in PTC cells. After confirming the key gene in PTC cells, the clinicopathologic association of miR-27a-3p and EDN3 in PTC cells was analyzed. miR-27a-3p or EDN3 was divided into the miR-27a-3p high-expression group $(n=15)$ and the low-expression group $(n=15)$ or the EDN3 high-expression group $(n=15)$ and the low-expression Group $(n=15)$. The expression level of miR-27a-3p or EDN3 was found to be associated with TNM stage, while only EDN3 expression was found to be correlated with the tumor diameter (Table I). Next, the expression of the key gene (END3) was explored in PTC cell lines (CUTC5, TPC-1, GLAG-66) 
A

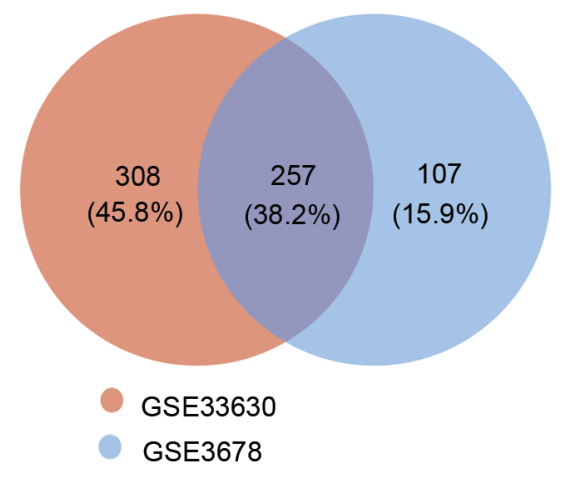

C
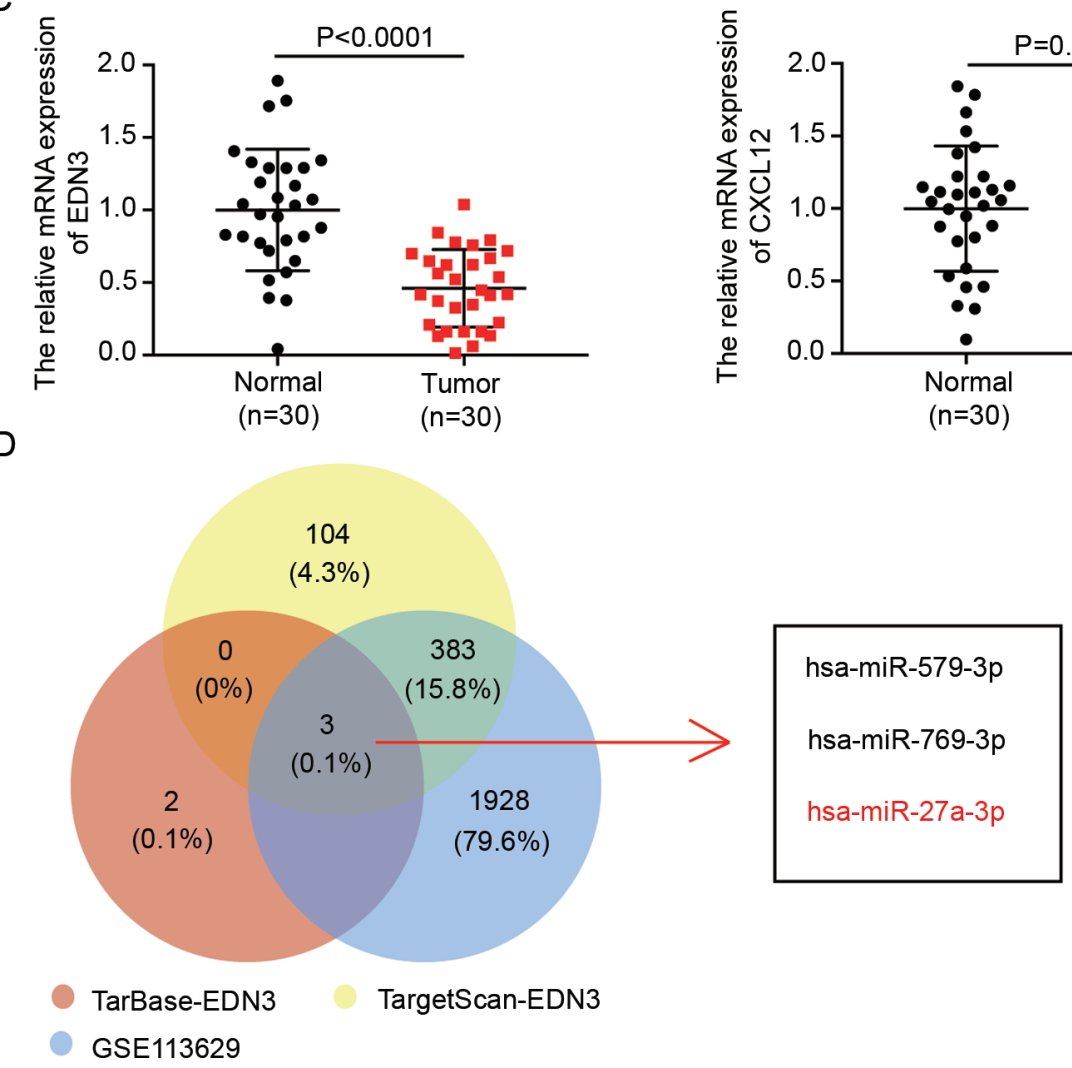

B
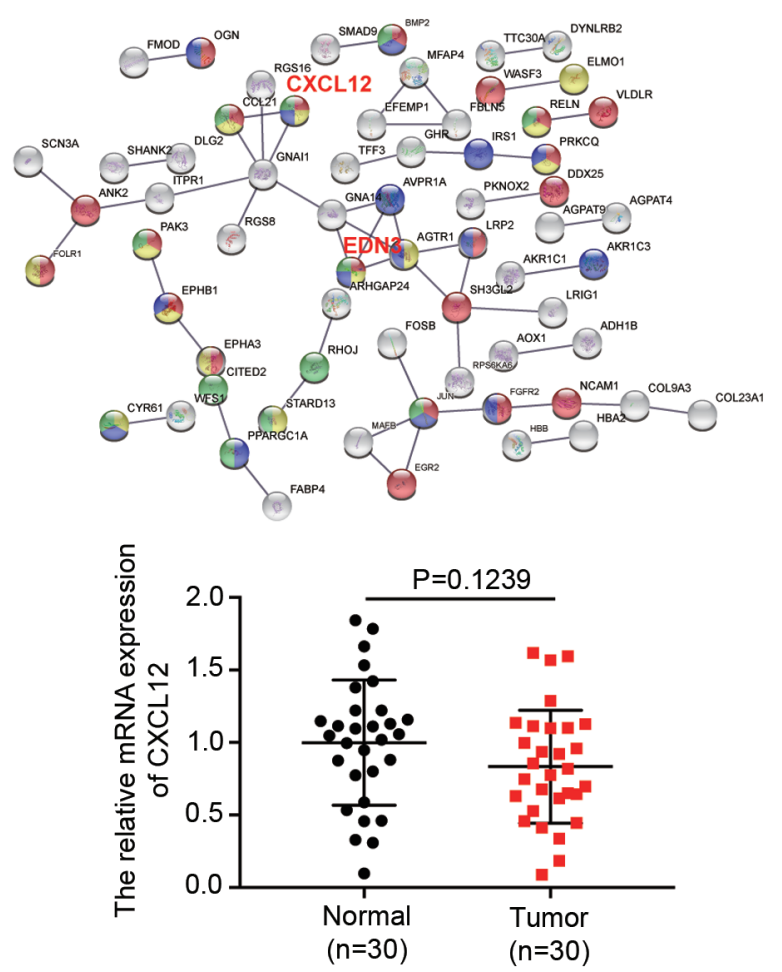

$(n=30)$

Figure 1. The key mRNAs and miRs associated with PTC. (A) The 257 DEGs were overlapped from two mRNA microarray (GSE33630 and GSE3678) analysis results. The DEGs were screened out using limma R package with adjusted P-value $<0.05$ and $\operatorname{logFC}<-1$. (B) CXCL12 and EDN3 were selected as participating in cell development, cell migration and cell proliferation by STRING database analysis of the 214 DEGs. The interaction score was set to highest confidence 0.900. (C) The expression of EDN3 and CXCL12 mRNA was detected in tissues specimens by reverse transcription-quantitative PCR. $\mathrm{n}=30$, Student's t-test. (D) Hsa-miR-579-3p, hsa-miR-769-3p and hsa-miR-27a-3p were overlapped from TarBase predicted targets of EDN3, TargetScan predicted targets of EDN3 and a miRNA microarray analysis result. TarBase-EDN3, the miRs binding to the END3 3'UTR were predicted by TarBase. TargetScan-EDN3, the miRs binding to the END3 3'UTR were predicted by TargetScan. GSE113629 miR expression microarray. miR, microRNA; PTC, papillary thyroid cancer; DEGs, differentially expressed genes; CXCL12, Chemokine Ligand 12; EDN, endothelin; UTR, untranslated region; has, human.

and the non-tumor thyroid cell line Nthy-ori 3-1. A significantly low level of EDN3 mRNA was observed in all the PTC cell lines using RT-qPCR, particularly in TPC-1 and GLAG-66 cells which exhibited $~ 80 \%$ decrease in EDN3 expression (Fig. 2A). Similar to the results of RT-qPCR, the results of western blot analysis indicated that the protein level of EDN3 decreased in PTC cell lines, particularly in TPC-1 and GLAG-66 which exhibited the lowest expression (Fig. 2B and C). Due to the significant downregulation of EDN3 in GLAG-66 and TPC-1 cells, these two PTC cell lines were selected to perform the subsequent experiments. Cell line models with forced overexpression of EDN3 and the corresponding $\mathrm{NC}$ model were obtained by respectively transfecting the EDN3-OE and NC plasmids into TPC-1 and GLAG-66 cells. The RT-qPCR results demonstrated that EDN3 expression increased by 2 -fold in the two PTC cell lines, an expression caused by EDN3-OE plasmids (Fig. 2D). EDN3 protein expression showed a similar result with the expression of EDN3 mRNA; EDN3-OE plasmids led to a $>2$-fold increase in EDN3 protein expression in these two PTC cell lines (Fig. 2E and F). The data suggested that EDN3 expression was downregulated in PTC cells and that EDN3-OE plasmids transfection successfully resulted in the upregulation of EDN3 in TPC-1 and GLAG-66 cells. 
A

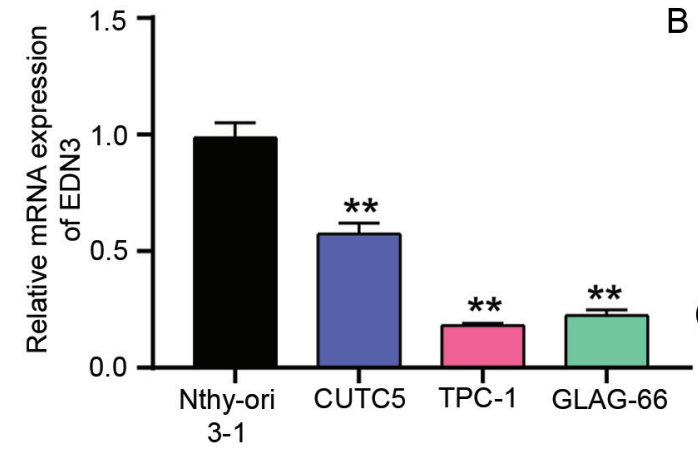

C

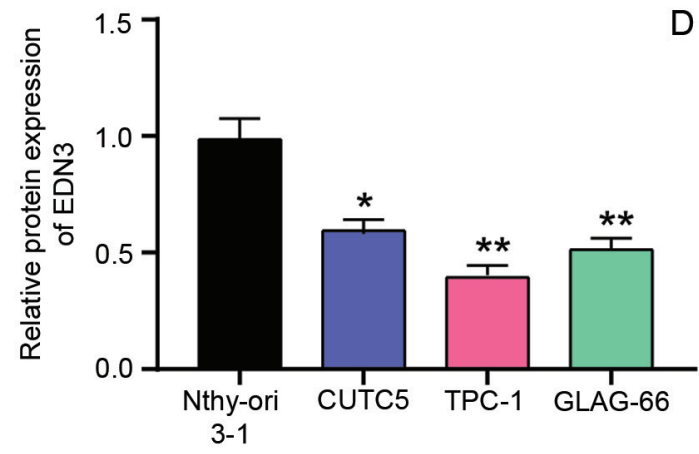

E

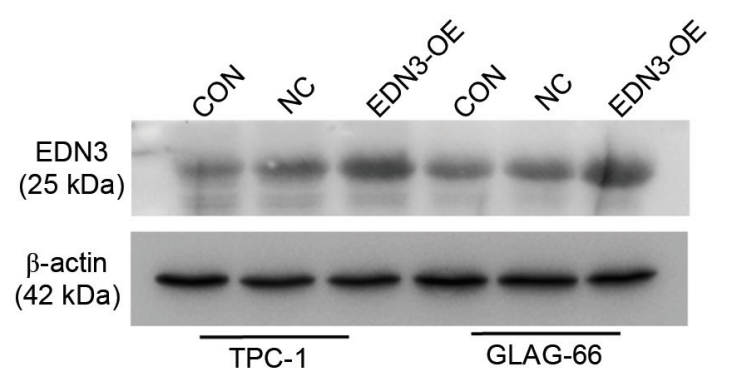

B
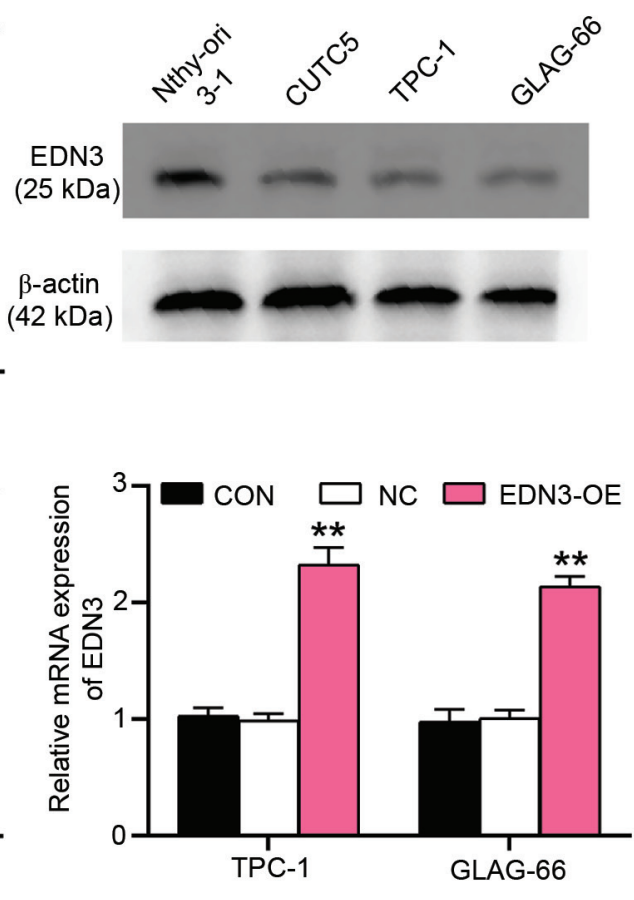

$F$

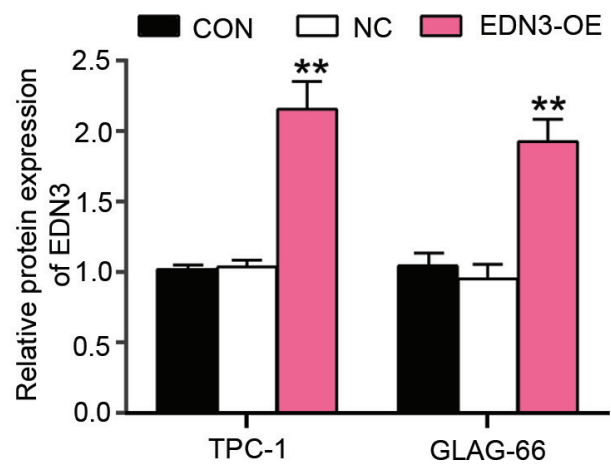

Figure 2. The expression of EDN3 is downregulated in the PTC cell lines. Nthy-ori 3-1 is a human thyroid cell line transformed by simian virus 40. CUTC5, TPC-1 and GLAG-66 cell lines were the PTC cell lines. (A) The relative expression of EDN3 mRNA was detected in Nthy-ori 3-1, CUTC5, TPC-1 and GLAG-66 cell lines. ${ }^{* *} \mathrm{P}<0.001$ vs. Nthy-ori 3-1 cell line using one-way ANOVA. (B and C) The protein level of EDN3 was detected by western blotting in Nthy-ori 3-1, CUTC5, TPC-1 and GLAG-66 cell lines. ${ }^{* *} \mathrm{P}<0.001$ vs. Nthy-ori 3-1 cell line using one-way ANOVA. (D) The relative expression of EDN3 mRNA was detected by reverse transcription-quantitative PCR in TPC-1 and GLAG-66 cells following transfection. ${ }^{* *} \mathrm{P}<0.001$ vs. control group. (E and F) The protein level of EDN3 was detected by western blotting in TPC-1 and GLAG-66 cells following transfection. ${ }^{* *} \mathrm{P}<0.001$ vs. control group. Each bar represented the standard deviation of three independent experiments. EDN, endothelin; PTC, papillary thyroid cancer; CON, TPC-1 and GLAG-66 cells cultured without any transfection; NC, TPC-1 and GLAG-66 cells transfected with negative control plasmids; EDN3-OE, TPC-1 and GLAG-66 cells transfected with EDN3-OE plasmids.

EDN3 overexpression in PTC cells impairs cell viability and proliferation but promotes cell apoptosis. Cytological experiments were performed to verify the roles of EDN3 in PTC cells. Experimental results revealed that cell viability was impaired after TPC-1 and GLAG-66 cells were transfected with EDN3-OE plasmids for 48 and 72 h (Fig. 3A). The BrdU cell proliferation assay outcome showed that EDN3-OE decreased OD value by $40 \%$ in both TPC-1 and GLAG-66 cell lines, thereby indicating that EDN3 overexpression impaired the proliferation of these PTC cells (Fig. 3B). As demonstrated in Fig. 3C, the caspase-3 activity was elevated by $>3$-fold in the PTC cells with the transfection of EDN3-OE plasmids. The apoptosis rate of PTC cells was also detected using flow cytometry and the results revealed that following upregulation of EDN3, the apoptosis rate of TPC-1 and GLAG cells increased by $\sim 2.5$ and 2 times, respectively (Fig. 3D and E).

EDN3 overexpression in PTC cells impairs cell migration and invasion. Wound healing assay was performed to explore the effect of EDN3 on cell migration. The findings demonstrated that EDN3-OE plasmids transfected into the two PTC cell lines decreased the migration rate at 24 and $48 \mathrm{~h}$ (Fig. 4A and B). To detect the invasiveness of TPC-1 and GLAG-66 cells, Transwell assay was performed and the result indicated that the number of cells invaded decreased by $\sim 30$ and $60 \%$ after transfection with EDN3-OE (Fig. 4C and D). Collectively, the results demonstrated that the EDN3 served a positive role in inhibiting the mobility phenotypes of PTC cells. 

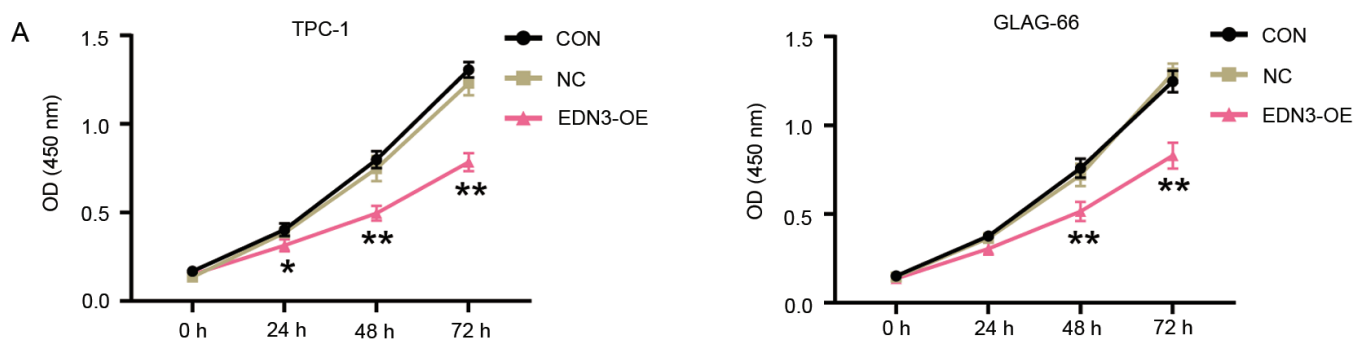

B

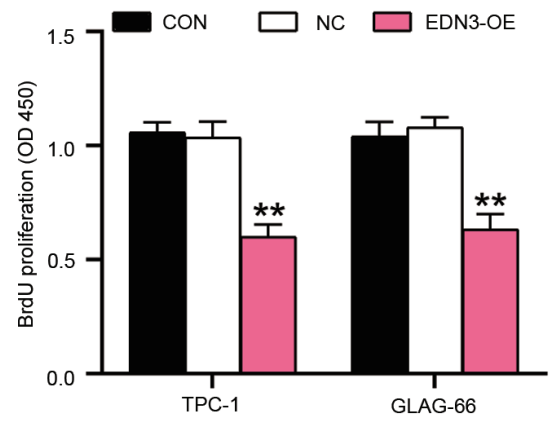

D

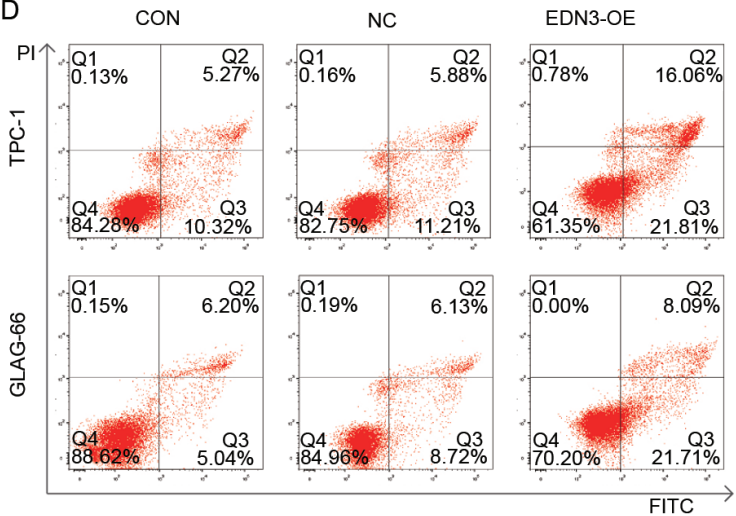

C

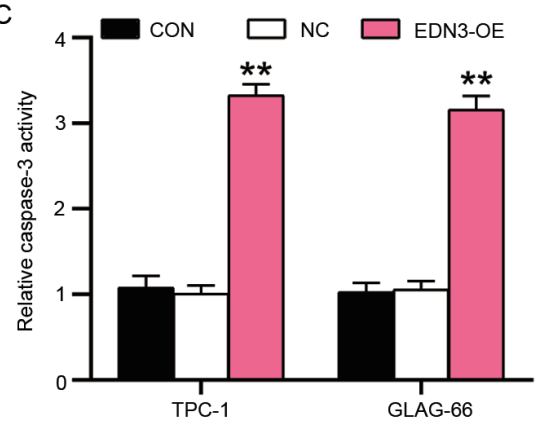

$\mathrm{E}$

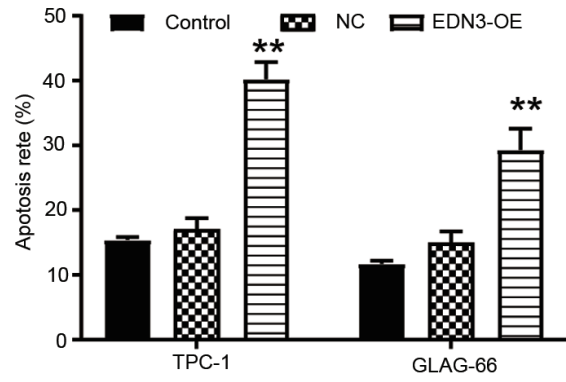

Figure 3. EDN3 overexpression inhibits viability and proliferation but induces cell apoptosis. (A) CCK8 assay was performed to determine the effect of EDN3 on the cell viability after TPC-1 and GLAG-66 cells were transfected with EDN3-OE plasmids or NC plasmids for 0, 24, 48 and $72 \mathrm{~h}$. (B) BrdU cell proliferation assay (a colorimetric method) was used to measure the effect of EDN3 on the cell proliferation after TPC-1 and GLAG-66 cells were transfected with EDN3-OE plasmids or NC plasmids at $72 \mathrm{~h}$. (C) The caspase-3 activation was detected using caspase-3 assay kit (a colorimetric method) to reflect the apoptosis of TPC-1 and GLAG-66 cells transfected with EDN3-OE or NC. (D and E) The apoptosis rate of TPC-1 and GLAG-66 cells transfected with EDN3-OE plasmids or $\mathrm{NC}$ plasmids was measured by flow cytometry. ${ }^{*} \mathrm{P}<0.05,{ }^{*} \mathrm{P}<0.001$ vs. the control group using one-way ANOVA. The bar represented the standard deviation of three independent experiments. EDN, endothelin; EDN3-OE, TPC-1 and GLAG-66 cells transfected with EDN3-OE plasmids; NC, TPC-1 and GLAG-66 cells transfected with negative control plasmids; OD450, optical density of cells at $450 \mathrm{~nm}$; CON, TPC-1 and GLAG-66 cells were cultured without any treatments.

Negative regulation of EDN3 by $m i R-27 a-3 p$. TargetScan predicted that EDN3 3 'UTR existed as the binding site for miR-27a-3p (Fig. 5A). To further verify whether the binding site existed for miR-27a-3p, a luciferase reporter assay was performed and it was found that the luciferase activity of the co-transfection of EDN3 mRNA 3'UTR and miR-27a-3p mimic decreased by $36.6 \%$ in TPC-1 cells and $41.5 \%$ in GLAG-66 cells compared with the co-transfection of EDN3 3'UTR and NC (Fig. 5B). Then, miR-27a-3p expression was detected in 30 PTC tissues and 30 non-tumor tissues. The result revealed that the expression of miR-27a-3p in tumor tissues was 2.14-fold of that in non-tumor tissues (Fig. 5C). After performing a Pearson correlation analysis, a negative correlation between EDN3 mRNA expression and miR-27a-3p expression was observed in PTC tissues (Fig. 5D). miR-27a-3p expression in Nthy-ori 3-1, TPC-1 and GLAG-66 cell lines was detected. It was observed that miR-27a-3p expression increased by 2.3-fold in TPC-1 cells and 1.6-fold in GLAG-66 cells (Fig. 5E). To explore the effect of miR-27a-3p on EDN3 expression, miR-27a-3p mimic was used to upregulate miR-27a-3p. After 48 h transfection, miR-27a-3p expression was upregulated by $>3$-fold in PTC cells, while the EDN3 expression was reduced by $\sim 65 \%$ in PTC cells (Fig. $5 \mathrm{~F}$ ). The downregulation of EDN3 by miR-27a-3p mimic transfection was also confirmed at protein level by western blot analysis; the protein expression of EDN3 declined by $40 \%$ in TPC-1 and GLAG-66 cells (Fig. 5G and H). These findings suggested that EDN3 mRNA 3'UTR exited the binding site for miR-27a-3p and that the overexpressed miR-27a-3p could suppress the EDN3 expression.

miR-27a-3p promotes the viability and proliferation of PTC cells and inhibits cell apoptosis by attenuating the effect of EDN3 on PTC cells. To explore how miR-27a-3p affected the phenotypes of PTC cells by regulating EDN3, a series of cytological experiments were performed. The results of cell 
A

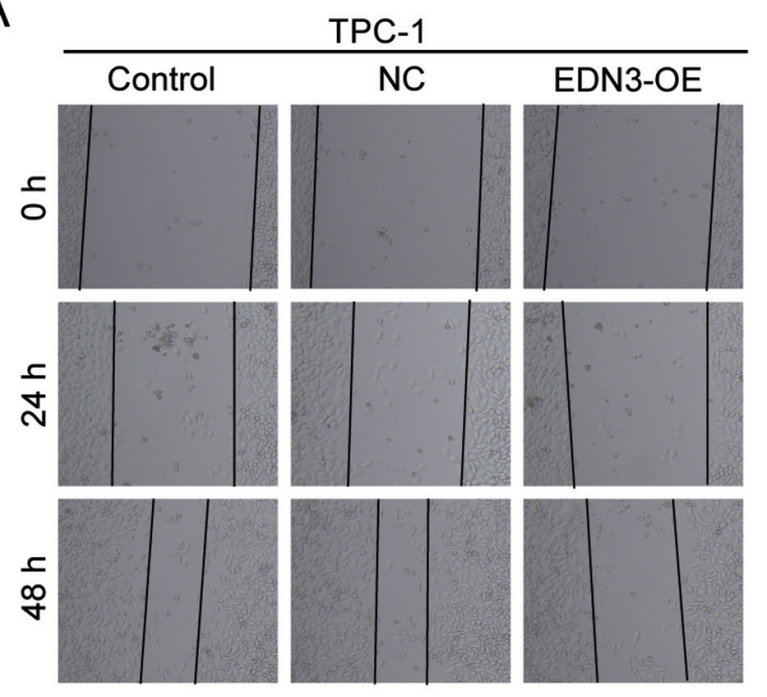

B

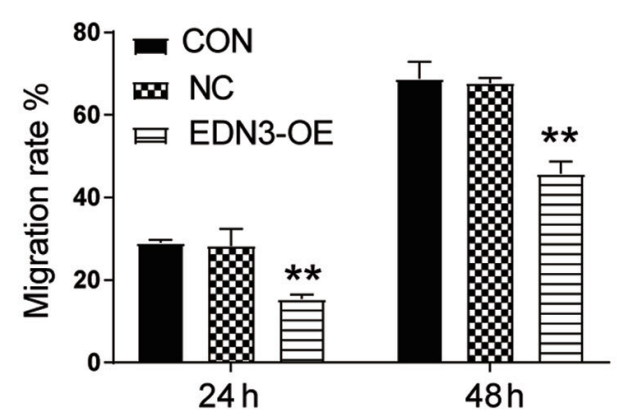

C

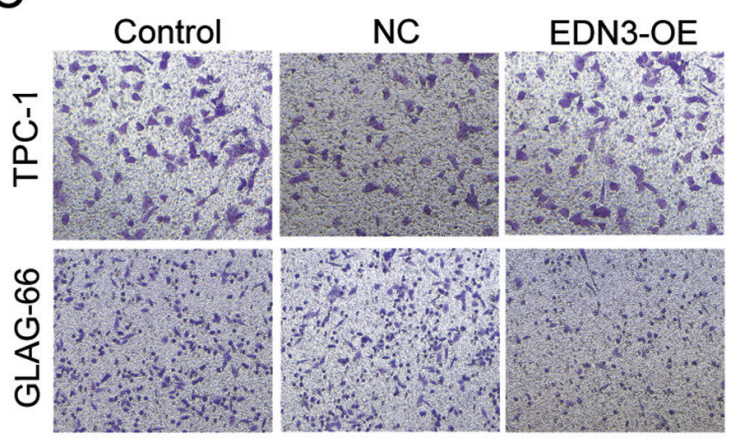

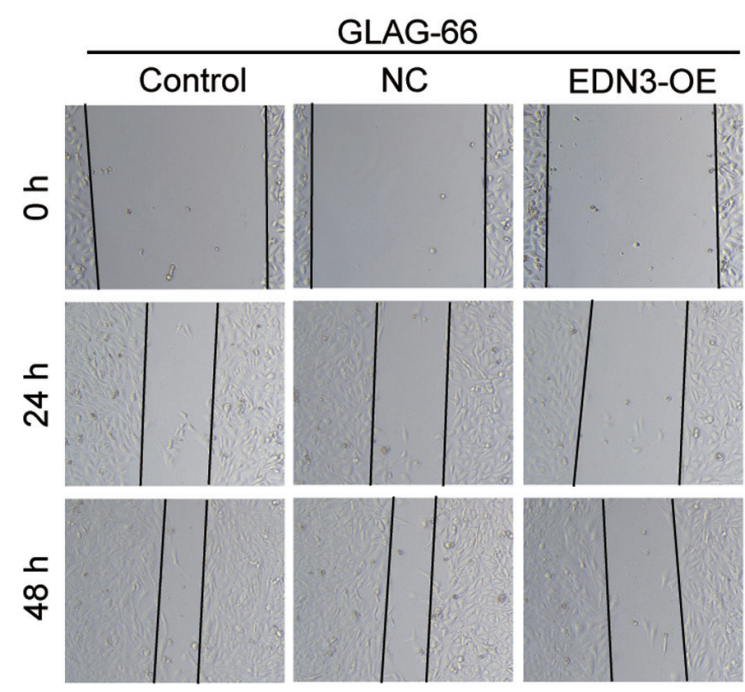
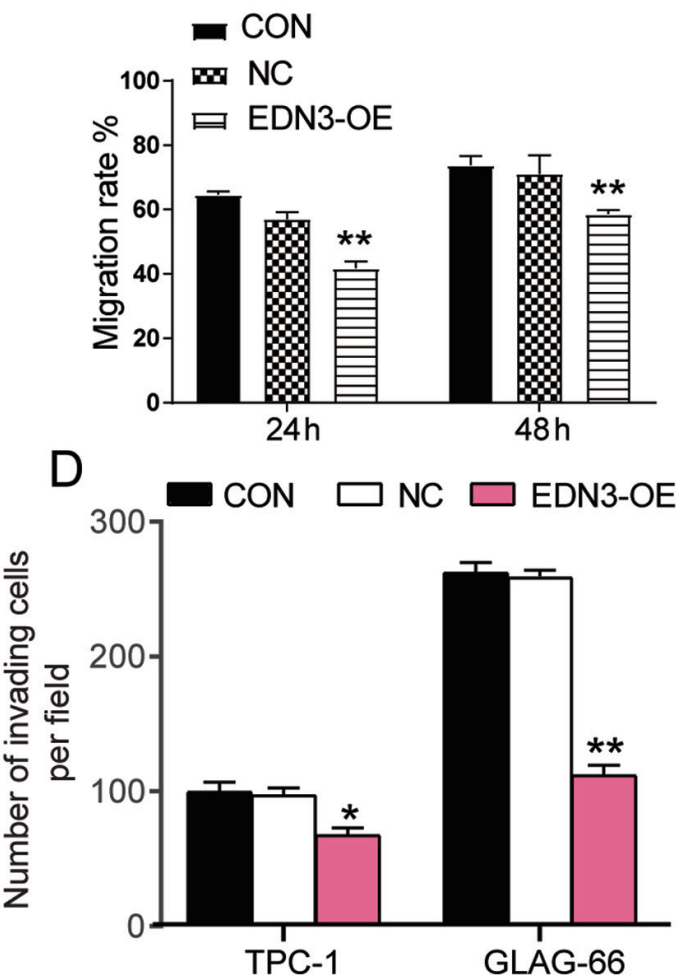

Figure 4. EDN3 overexpression inhibits the migration and invasion of PTC cells. (A and B) The ability of cell migration was assessed using wound healing assay following transfection of the TPC-1 and GLAG-66 cells for 24 and $48 \mathrm{~h}$. Magnification, x100. (C and D) Transwell assay was used to verify the invasion phenotype of TPC-1 and GLAG-66 cells following transfection with EDN3-OE plasmids or NC plasmids. Magnification, $\mathrm{x} 100$. ${ }^{*} \mathrm{P}<0.05$, ${ }^{* *} \mathrm{P}<0.001$ vs. the control group using one-way ANOVA. The bar represented the standard deviation of three independent experiments. EDN, endothelin; PTC, papillary thyroid cancer; EDN3-OE, TPC-1 and GLAG-66 cells transfected with EDN3-OE plasmids; NC, TPC-1 and GLAG-66 cells transfected with negative control plasmids; CON, TPC-1 and GLAG-66 cells were cultured without any treatments.

viability assay demonstrated that miR-27a-3p mimic increased cell viability after the PTC cells were transfected for 48 and $72 \mathrm{~h}$. However, the cell viability of the EDN3 and miR-27a-3p co-transfection group was similar to that of the control group in the two PTC cell lines. Nevertheless, compared with the co-transfection group, the cell viability in miR-27a-3p mimic group was significantly higher whereas that in EDN3-OE group was significantly lower (Fig. 6A). As with the cell viability, cell proliferation (reflected by the OD value) was enhanced by $\sim 1.7$-fold in PTC cells transfected with miR-27a-3p mimic compared with the control group $\left({ }^{*} \mathrm{P}<0.05,{ }^{* *} \mathrm{P}<0.01\right)$ or co-transfection group $\left({ }^{\#} \mathrm{P}<0.05,{ }^{\# \#} \mathrm{P}<0.01\right)$, while the cell proliferation in EDN3-OE group showed significantly lower OD450 value than that in co-transfection group (Fig. 6B). The cell apoptosis (both caspase-3 activation and flow cytometry assays) results revealed that in the miR-27a-3p mimic group, the apoptosis decreased significantly, whereas the apoptosis increase significantly in EDN3-OE group compared with the control group and the co-transfection group (Fig. 6C-E).

EDN3 overexpression partially reverses the stimulating effects of miR-27a-3p on cell migration and invasion. The 
A

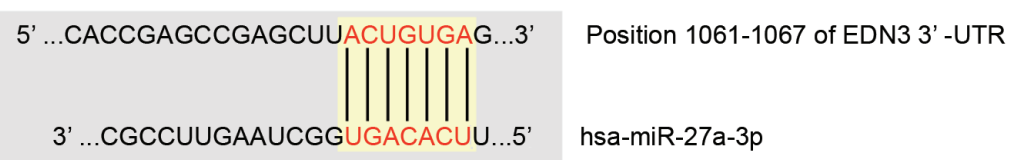

B
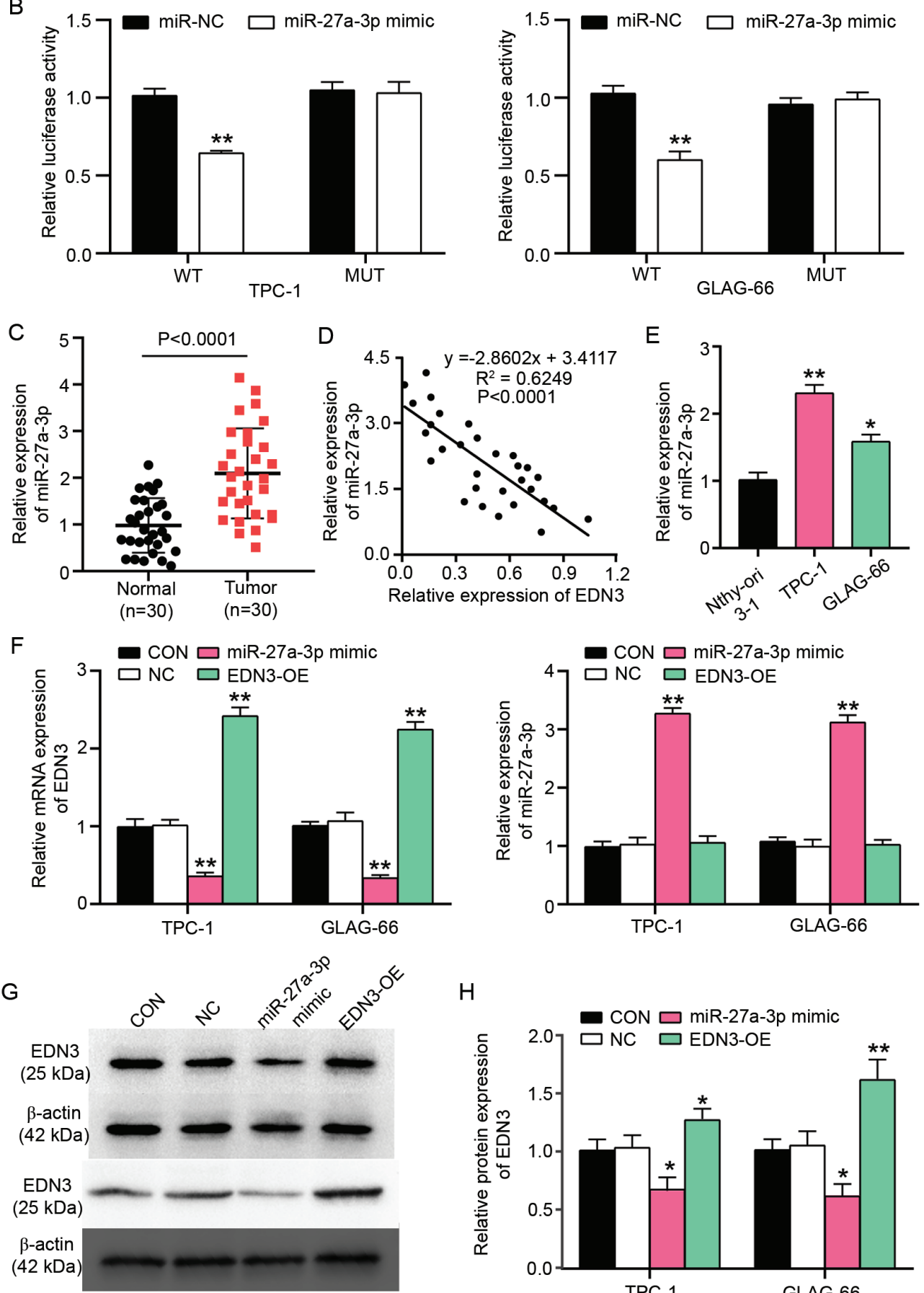

$\mathrm{H}$

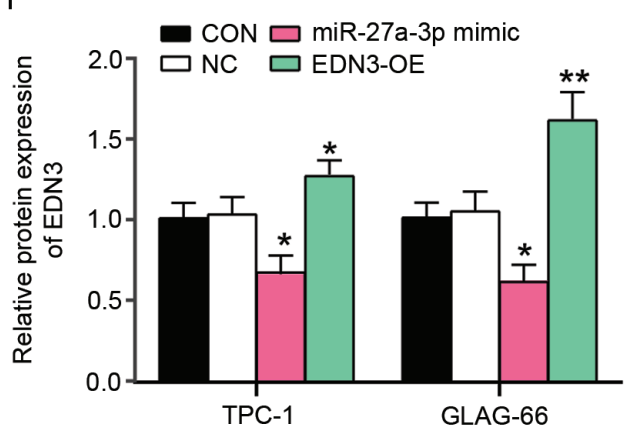

Figure 5. EDN3 is the target gene of miR-27a-3p. (A) The binding site between EDN3 mRNA 3'UTR and miR-27a-3p as predicted by TargetScan. (B) The binding site between EDN3 mRNA 3'UTR and miR-27a-3p was validated in TPC-1 and GLAG-66 cells by luciferase reporter assay. ${ }^{* *} \mathrm{P}<0.001$ vs. the co-transfection of WT EDN3 3'UTR vectors and miR-27a-3p mimic using one-way ANOVA. (C) The expression of miR-27a-3p in tissue specimens was detected by RT-qPCR. n=30, Student's t-test. (D) The correlation between EDN3 mRNA expression and miR-27a-3p expression in 30 tissue specimens was analyzed by Pearson correlation analysis. (E) The relative expressions of miR-27a-3p was detected in Nthy-ori 3-1, TPC-1 and GLAG-66 cell lines by RT-qPCR. Nthy-ori 3-1 is a human thyroid cell line transformed by simian virus 40 . TPC-1 and GLAG-66 cell lines are PTC cell lines. ${ }^{*} \mathrm{P}<0.05,{ }^{* * *} \mathrm{P}<0.001$ vs. Nthy-ori 3-1 cell line using one-way ANOVA. (F) The relative expression of EDN3 mRNA and miR-27a-3p was detected in TPC-1 and GLAG-66 cell lines by RT-qPCR. $(\mathrm{G}$ and $\mathrm{H})$ The relative protein expressions of EDN3 was detected in TPC-1 and GLAG- 66 cell lines by western blotting. ${ }^{*} \mathrm{P}<0.05,{ }^{* *} \mathrm{P}<0.001$ vs. control group using one-way ANOVA. The bar represented the standard deviation of at least three independent experiments. EDN, endothelin; miR, microRNA; UTR, untranslated region; WT, wild-type EDN3 mRNA 3'UTR vectors. MUT, mutated EDN3 mRNA 3'UTR vectors; RT-qPCR, reverse transcription-quantitative PCR; PTC, papillary thyroid cancer; CON, TPC-1 and GLAG-66 cells were cultured without any treatments; NC, TPC-1 and GLAG-66 cells were transfected with negative control plasmids; EDN3-OE, TPC-1 and GLAG-66 cells were transfected with EDN3-OE plasmids; miR-27a-3p, TPC-1 and GLAG-66 cells were transfected with miR-27a-3p mimic. 

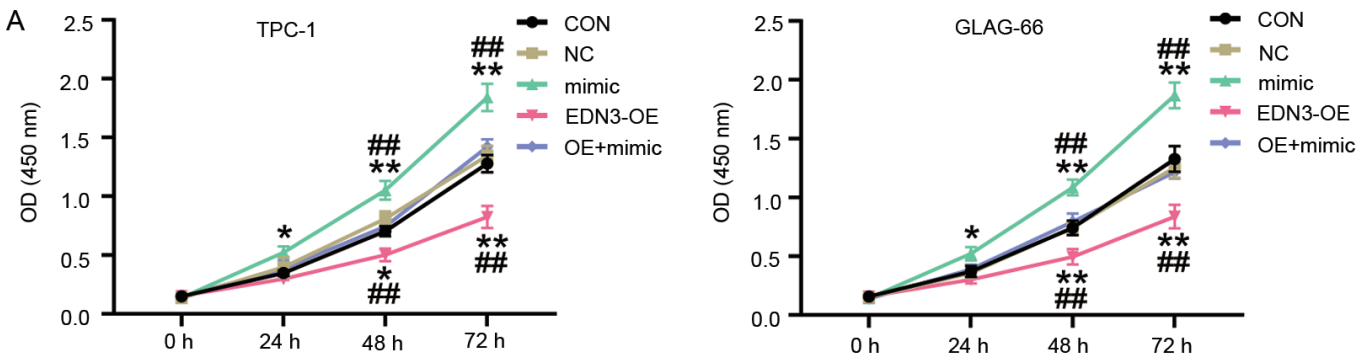

B

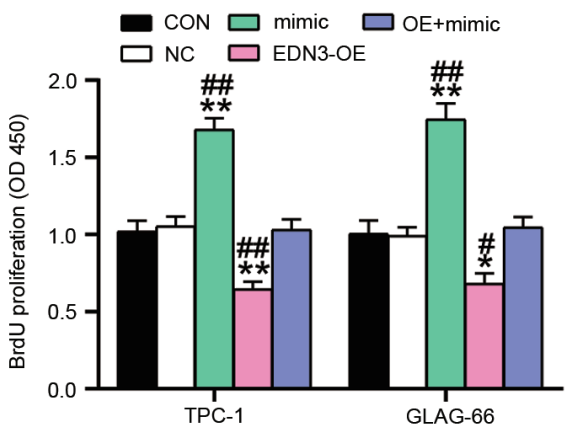

C

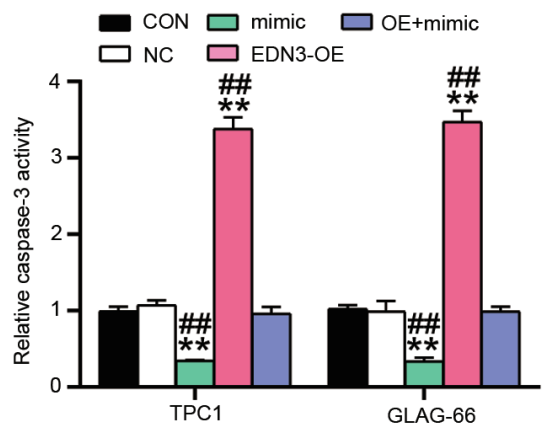

D

CON

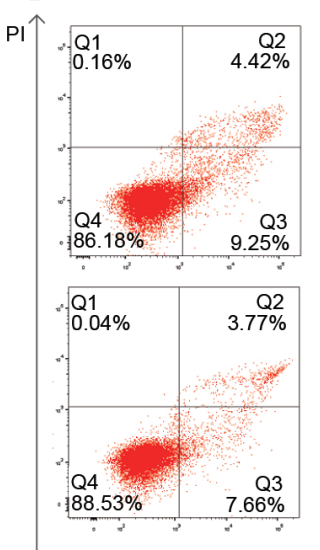

\begin{abstract}
NC
\end{abstract}

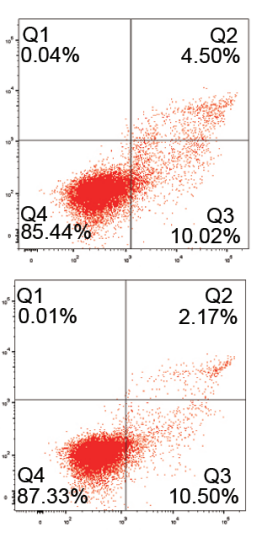

\section{E}

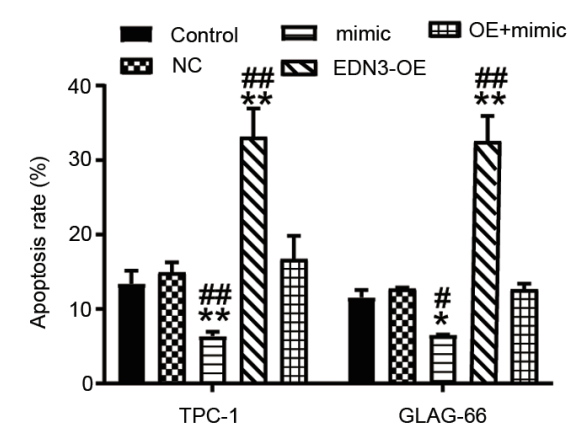

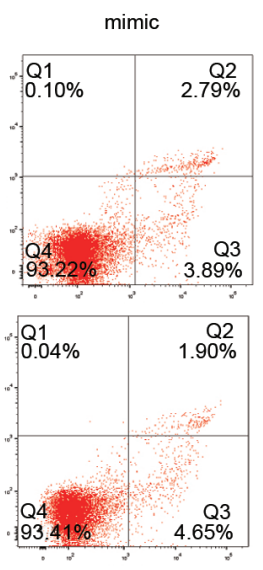
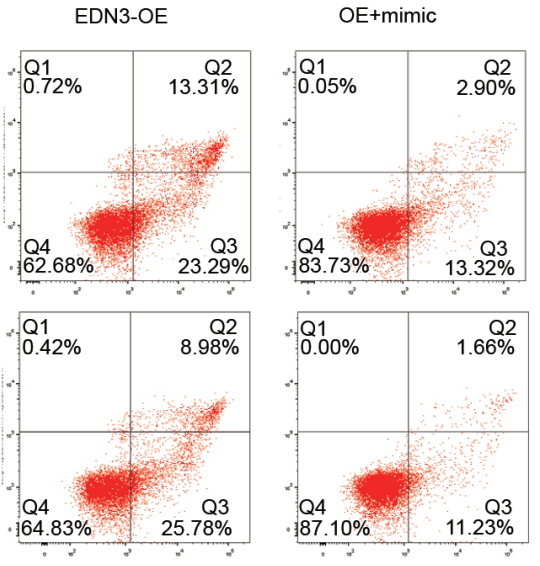

FITC

Figure 6. miR-27a-3p enhanced the cancer phenotypes of PTC cells and by inhibiting EDN3. (A) CCK8 assay was performed to determine the viability of TPC-1 and GLAG-66 cells after transfection for $0,24,48$ and $72 \mathrm{~h}$. (B) BrdU cell proliferation assay was used to determine the cell proliferation $72 \mathrm{~h}$ following the transfection of TPC-1 and GLAG-66 cells. (C) The caspase-3 activation was detected using caspase-3 assay kit to reflect the apoptosis of TPC-1 and GLAG-66 cells in each group. (D and E) The apoptosis rate of TPC-1 and GLAG-66 cells was measured by flow cytometry. ${ }^{*} \mathrm{P}<0.05,{ }^{* *} \mathrm{P}<0.001$ vs. control group using one-way ANOVA. ${ }^{\#} \mathrm{P}<0.05,{ }^{\# \#} \mathrm{P}<0.001$ vs. $\mathrm{OE}+$ mimic group using one-way ANOVA. The bar represented the standard deviation of at least three independent experiments. miR, microRNA; EDN, endothelin; PTC, papillary thyroid cancer; CON, TPC-1 and GLAG-66 cells were cultured without any treatments; NC, TPC-1 and GLAG-66 cells were transfected with negative control plasmids; EDN3-OE, TPC-1 and GLAG-66 cells were transfected with EDN3-OE plasmids; OE + mimic, TPC-1 and GLAG-66 cells were co-transfected with EDN3-OE plasmids and miR-27a-3p mimic.

cell migration rate (calculated as described in the methods section) and invasion numbers were detected to reflect the effects of miR-27a-3p on mobility phenotypes of PTC cells by regulating EDN3. Wound-healing assay results demonstrated that, compared with the control and co-transfection groups, the migration rate of PTC cells increased after overexpressing miR-27a-3p but decreased after upregulating EDN3 (Fig. 7A and B). The Transwell assay results revealed that the invasion was enhanced (by 1.6-fold in GLAG-66 cell line and 1.3-fold in TPC-1 cell line) in the miR-27a-3p mimic group 
A
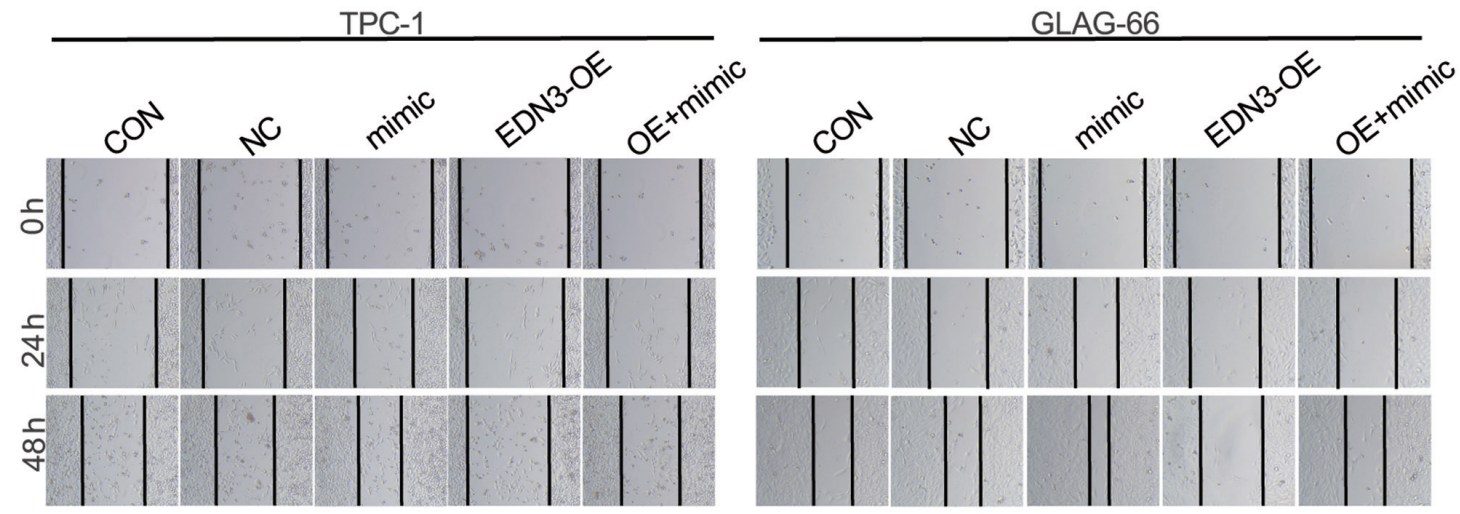

B
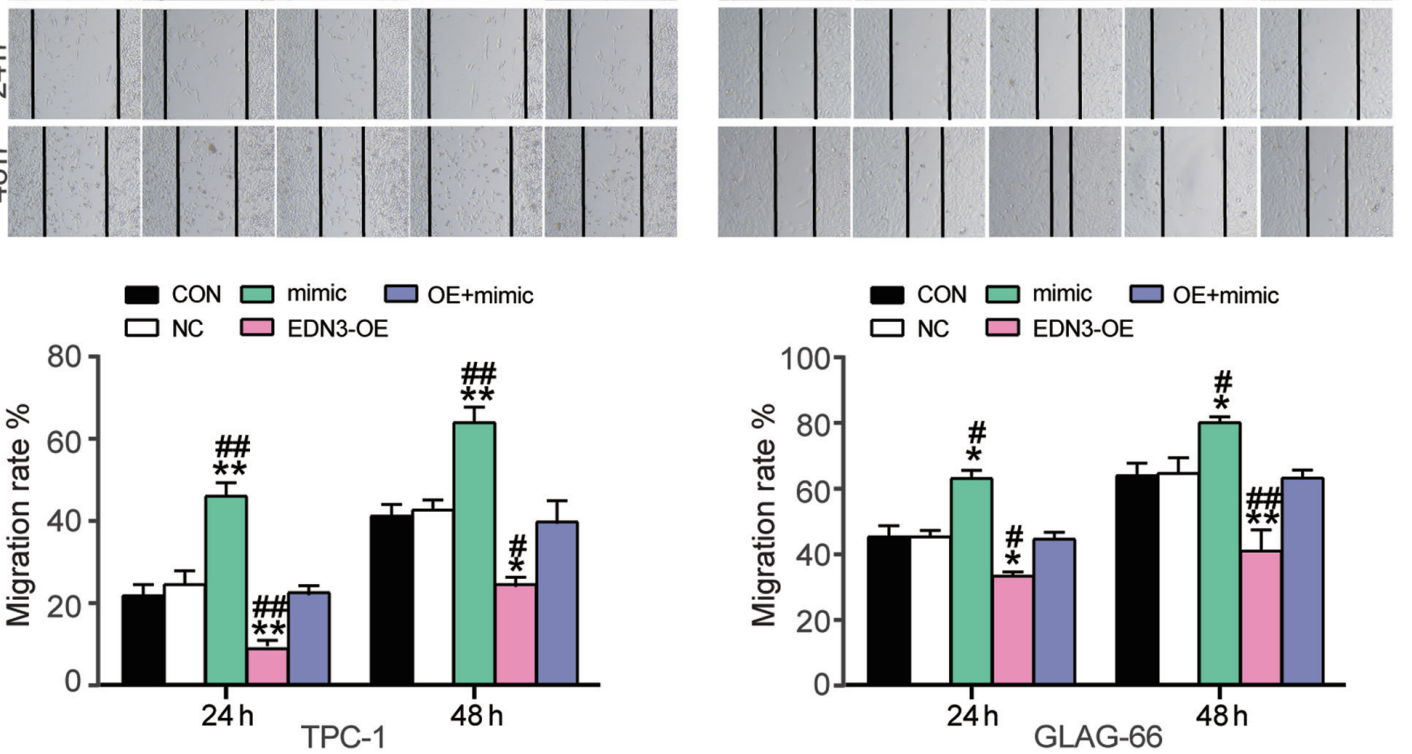

C

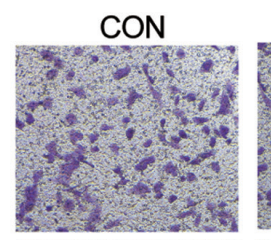

NC
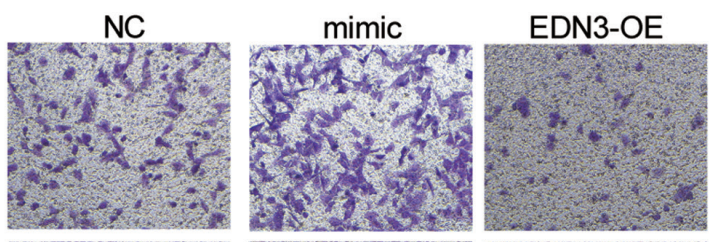

$\square$ CON $\square$ mimic $\square$ OE+mimic
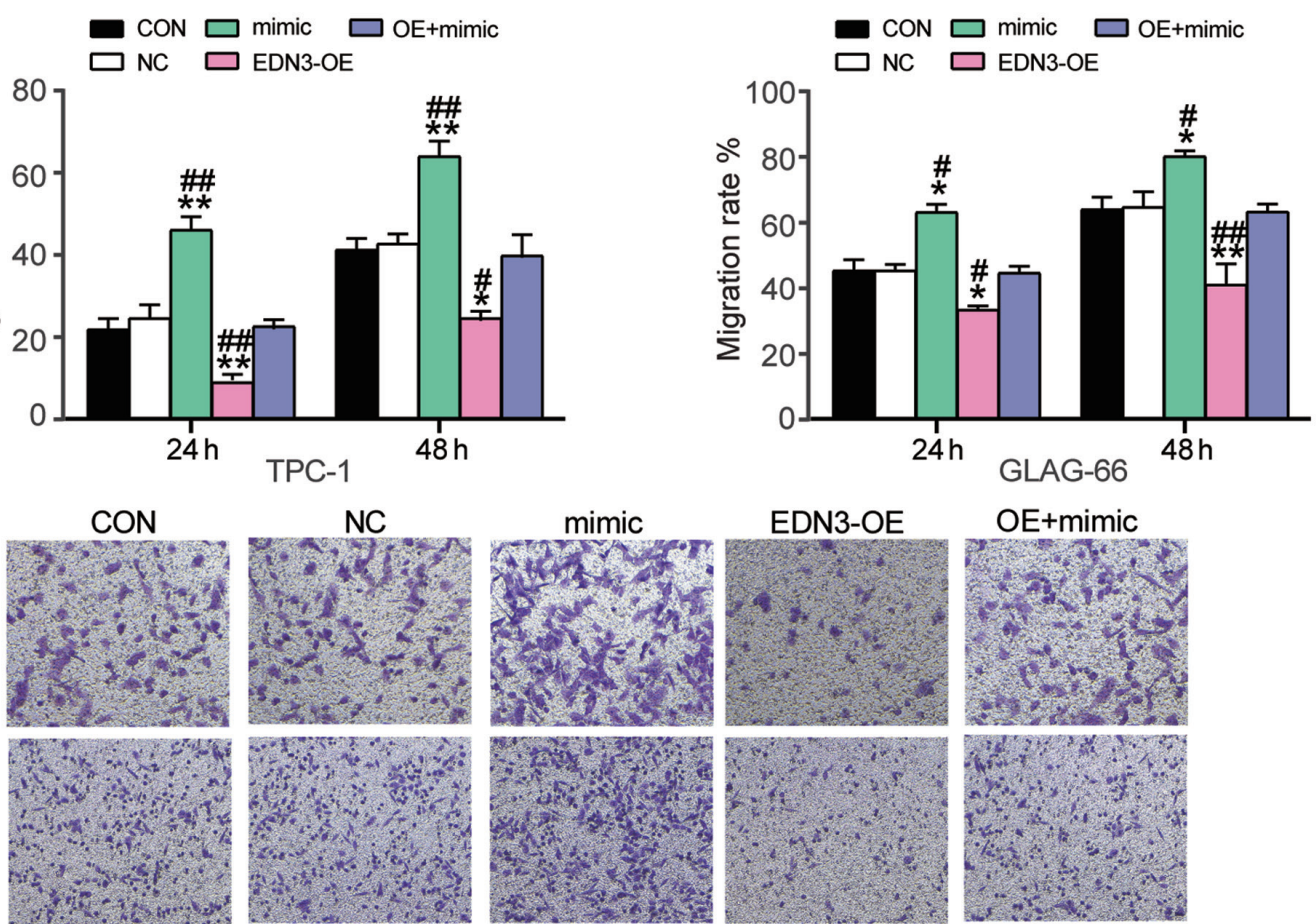

D

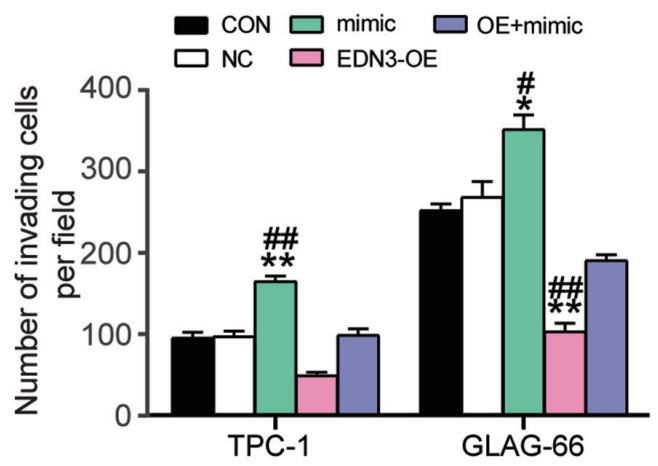

Figure 7. Overexpression of EDN3 reversed the promoting effects of miR-27a-3p on PTC cell migration and invasion. (A and B) Wound healing assay was conducted to measure the cell migration 24 and $48 \mathrm{~h}$ after the transfection. Magnification, x100. (C and D) The number of invading cells was detected using Transwell assay to reflect the invasion ability of TPC-1 and GLAG-66 cells. Magnification, $\mathrm{x} 100 .{ }^{*} \mathrm{P}<0.05,{ }^{* * *} \mathrm{P}<0.001$ vs. control group using one-way method. ${ }^{\#} \mathrm{P}<0.05,{ }^{\#} \mathrm{P}<0.001 \mathrm{vs}$. OE + mimic group using one-way ANOVA. The bar represented the standard deviation of at least three independent experiments. EDN, endothelin; PTC, papillary thyroid cancer; CON, TPC-1 and GLAG-66 cells were cultured without any treatments; NC, TPC-1 and GLAG-66 cells were transfected with negative control plasmids; EDN3-OE, TPC-1 and GLAG-66 cells were transfected with EDN3-OE plasmids; mimic, TPC-1 and GLAG-66 cells were transfected with miR-27a-3p mimic; OE + mimic, TPC-1 and GLAG-66 cells were co-transfected with EDN3-OE plasmids and miR-27a-3p mimic.

and the invasion was suppressed in cells of the EDN3-OE group, compared with the control and the co-transfection groups (Fig. 7C and D). Overall, these data demonstrated that
miR-27a-3p was a carcinogenic factor in PTC progression and its upregulation could attenuate the inhibitory effect of EDN3 on PTC cells. 


\section{Discussion}

Using gene microarray analysis, the present study identified that EDN3 and CXCL12 were associated with PTC. Following the detection of the mRNA expression of EDN3 and CXCL12 in PTC tissue samples, EDN3 was finally chosen as the gene of interest as EDN3 expression was very low in PTC tissues. miRNA microarray analysis was then performed and miR-27a-3p selected as the miR of interest. The cell-function experiments indicated that EDN3 overexpression in PTC cells could decrease cell viability, inhibit cell proliferation and migration and enhance cell apoptosis. It was also found that miR-27a-3p could enhance the tumorigenic phenotypes of PTC cells by binding to EDN3 mRNA 3'UTR to suppress the EDN3 expression.

Increasing evidence confirms that the miR-27a family serve a key role in regulating cancer phenotypes including invasion, migration, angiogenesis and apoptosis (40-44). In thyroid cancer, Wang et al (38) established a thyroid cancer xenograft model and demonstrated that miR-27a upregulation promoted the expression of inducible nitric oxide synthase (an early marker of angiogenesis) and angiogenesis. They also performed cell-function experiments in vitro and proved that the upregulation of miR-27a contributed to cell migration and invasion. Even so, the effects of miR-27a-3p in PTC remains to be elucidated. Following bioinformatics analysis, miR-27a-3p was selected as the key miRNA that might be closely associated with PTC development. A series of cytological experiments were later performed to explore the role of miR-27a-3p and it was discovered that the biological function of miR-27a-3p in PTC was to promote PTC cell viability and proliferation while inhibiting apoptosis.

EDNs exert their functions by interacting with their cognate receptors (ETAR and ETBR), thus mediating fundamental processes in tissue differentiation, repair and growth (45). EDN1 and EDN3 primarily interact with ETAR and ETBR, respectively (46). EDN1 has been reported to be produced by endothelial cells, vascular smooth muscle cells, epithelial cells, hepatocytes and neurons (47). By binding with ETa, this protein participates in vasoconstriction, bronchoconstriction, mitogenesis, neuropathic pain, electrolyte balance, matrix formation and synergism (48). In addition, EDN1 has been found to participate in cancer pathways by activating various kinases, inhibiting apoptosis, affecting metastasis and contributing to angiogenesis (45). By contrast, EDN3 primarily originates from epithelial cells, adrenal cells and neurons (48). By interacting with ETb, EDN3 frequently affects EDN1 autoinduction, angiogenesis, inflammatory pain, endothelin clearance and vasodilation $(45,46)$.

Notably, EDN1 can directly affect the phenotypes of cancer cells by stimulating cell proliferation, migration, invasion and inhibiting cell apoptosis $(14,15)$. Its overexpression is found in cells with thyroid cancer and its overexpression can contribute to thyroid cancer progression $(17,18)$. As for PTC, a specific polymorphism of EDN1 is reported to increase the risk of PTC development (49). In addition, the relationship between EDN1 and miR-27a has been reported in pulmonary function studies. It was demonstrated that the more miR-27a in a sickle cell mouse lung increased, the more EDN1 increased (50). It is also documented that
EDN1 induced the expression of miR-27a in the proliferation of pulmonary artery smooth muscle cells (PASMC) (51,52). Taken together, the evidence indicates that EDNs may be related to miR-27a.

However, a recent study suggests that EDN3 is silent in breast cancer (21), colon cancer (20) and cervical cancer (53) suggesting that EDN3 may be a tumor suppressor gene in breast cancer and colon cancer. There is evidence that the downregulation of EDN3 is associated with PTC staging (23). The present study validated the downregulation of EDN3 in PTC tissues and cell lines. The overexpression of EDN3 impeded the viability, proliferation and cell migration but induced cell apoptosis of both TPC-1 and GLAG66 cell lines. The findings of the present study may contribute to the understanding of the role of EDN3 in PTC based on the experimental results.

The present study is not without limitations. In terms of prognosis analysis, the correlation between the expression of miR-27a-3p and EDN3 and the prognosis of patients with PTC was not statistically analyzed, given that recently diagnosed patients with PTC were selected. In addition, the sample size of the participants was small. The present study did not have sufficient numbers of patients for the follow-up prognosis study. These issues, however, will be addressed in future studies.

The present study identified the positive effects of miR-27a-3p and the negative effects of EDN3 on PTC cell phenotypes in vitro. However, their effects on PTC cells in vivo were not been explored because of the limitations of the experimental conditions. In addition, considering the significant role of EDN3 in PTC cells, the mechanism of how EDN3 regulates PTC progression needs to be further confirmed. Although the present study found close associations between EDN3 expression and miR-27a-3p expression with TNM stage as well as the association between EDN3 expression and tumor diameter, the correlation between the expression of miR-27a-3p and EDN3 and the prognosis of patients with PTC was not been statistically analyzed as recently diagnosed patients with PTC were selected and there were not enough patients to follow up. These problems be addressed in future research.

The present study demonstrated that the upregulation of EDN3 in PTC cells suppressed the cell viability of TPC-1 and GLAG-66 and impaired cell proliferation and migration. It also revealed that EDN3 overexpression promoted cell apoptosis. In addition to the fact that miR-27a-3p was found to be a tumor promoter in PTC cells, miR-27a-3p was discovered to attenuate the negative effect of EDN3 on PTC cells by binding to EDN3 mRNA 3'UTR. Overall, the present study demonstrated the significance of miR-27a-3p and EDN3 in PTC cells.

\section{Acknowledgements}

Not applicable.

\section{Funding}

No funding was received.

\section{Availability of data and materials}

The datasets used and/or analyzed during the current study are available from the corresponding author on reasonable request. 


\section{Authors' contributions}

$\mathrm{HC}, \mathrm{BC}, \mathrm{KL}$ and $\mathrm{QH}$ performed the experiments and data analysis. $\mathrm{HC}$ conceived and designed the study. BC and $\mathrm{KL}$ are responsible for confirming the authenticity of the data. All authors read and approved the manuscript.

\section{Ethics approval and consent to participate}

The present study was approved by the Ethics Committee of Wuhan Puren Hospital (approval no. A01401-LL201912-002). All patients signed written informed consent.

\section{Patient consent for publication}

Not applicable.

\section{Competing interests}

The authors declare that they have no competing interests.

\section{References}

1. Carneiro RM, Carneiro BA, Agulnik M, Kopp PA and Giles FJ Targeted therapies in advanced differentiated thyroid cancer Cancer Treat Rev 41: 690-698, 2015.

2. Siegel RL, Miller KD and Jemal A: Cancer statistics, 2015. CA Cancer J Clin 65: 5-29, 2015.

3. Torre LA, Bray F, Siegel RL, Ferlay J, Lortet-Tieulent J and Jemal A: Global cancer statistics, 2012. CA Cancer J Clin 65 87-108, 2015.

4. Tuttle RM: Controversial issues in thyroid cancer management J Nucl Med 59: 1187-1194, 2018.

5. Bates MF, Lamas MR, Randle RW, Long KL, Pitt SC, Schneider DF and Sippel RS: Back so soon? Is early recurrence of papillary thyroid cancer really just persistent disease? Surgery 163: 118-123, 2018

6. Zhang $\mathrm{H}$ and $\mathrm{Hu} \mathrm{N}$ : Telomerase reverse transcriptase induced thyroid carcinoma cell proliferation through PTEN/AKT signaling pathway. Mol Med Rep 18: 1345-1352, 2018.

7. Grimshaw MJ: Endothelins and hypoxia-inducible factor in cancer. Endocr Relat Cancer 14: 233-244, 2007.

8. Rubanyi GM and Polokoff MA: Endothelins: Molecular biology, biochemistry, pharmacology, physiology, and pathophysiology. Pharmacol Rev 46: 325-415, 1994.

9. Grimshaw MJ, Hagemann T, Ayhan A, Gillett CE, Binder C and Balkwill FR: A role for endothelin-2 and its receptors in breast tumor cell invasion. Cancer Res 64: 2461-2468, 2004.

10. Smollich $M$ and Wülfing P: The endothelin axis: A novel target for pharmacotherapy of female malignancies. Curr Vasc Pharmacol 5: 239-248, 2007.

11. Pollock DM, Keith TL and Highsmith RF: Endothelin receptors and calcium signaling. FASEB J 9: 1196-1204, 1995.

12. Bagnato A and Catt KJ: Endothelins as autocrine regulators of tumor cell growth. Trends Endocrinol Metab 9: 378-383, 1998.

13. Bagnato A, Spinella $F$ and Rosanò L: Emerging role of the endothelin axis in ovarian tumor progression. Endocr Relat Cancer 12: 761-772, 2005.

14. Bagnato A and Rosanò L: The endothelin axis in cancer. Int J Biochem Cell Biol 40: 1443-1451, 2008

15. Irani S, Salajegheh A, Smith RA and Lam AK: A review of the profile of endothelin axis in cancer and its management. Crit Rev Oncol Hematol 89: 314-321, 2014.

16. Tilly N, Schneider JG, Leidig-Bruckner G, Sommer U and Kasperk C: Endothelin-1 levels in patients with disorders of the thyroid gland. Exp Clin Endocrinol Diabetes 111: 80-84, 2003.

17. Donckier JE, Michel L, Delos M, Havaux X and Van Beneden R: Interrelated overexpression of endothelial and inducible nitric oxide synthases, endothelin-1 and angiogenic factors in human papillary thyroid carcinoma. Clin Endocrinol (Oxf) 64: 703-710, 2006.
18. Irani S, Salajegheh A, Gopalan V, Smith RA and Lam AK: Expression profile of endothelin 1 and its receptor endothelin receptor A in papillary thyroid carcinoma and their correlations with clinicopathologic characteristics. Ann Diagn Pathol 18: 43-48, 2014.

19. Olender J, Nowakowska-Zajdel E, Kruszniewska-Rajs C, Orchel J,Mazurek U, Wierzgoń A, Kokot T and Muc-Wierzgoń M: Epigenetic silencing of endothelin-3 in colorectal cancer. Int J Immunopathol Pharmacol 29: 333-340, 2016.

20. Wang R, Löhr CV, Fischer K, Dashwood WM, Greenwood JA, Ho E, Williams DE, Ashktorab H, Dashwood MR and Dashwood RH: Epigenetic inactivation of endothelin-2 and endothelin-3 in colon cancer. Int J Cancer 132: 1004-1012, 2013.

21. Wiesmann F, Veeck J, Galm O, Hartmann A, Esteller M, Knüchel R and Dahl E: Frequent loss of endothelin-3 (EDN3) expression due to epigenetic inactivation in human breast cancer. Breast Cancer Res 11: R34, 2009.

22. Liu Y, Ye F, Yamada K, Tso JL, Zhang Y, Nguyen DH, Dong Q, Soto H, Choe J,Dembo A, et al: Autocrine endothelin-3/endothelin receptor B signaling maintains cellular and molecular properties of glioblastoma stem cells. Mol Cancer Res 9: 1668-1685, 2011.

23. Qiu J, Zhang W, Zang C, Liu X, Liu F, Ge R, Sun Y and Xia Q: Identification of key genes and miRNAs markers of papillary thyroid cancer. Biol Res 51: 45, 2018.

24. Wang Q, Wang S, Wang H, Li P and Ma Z: MicroRNAs: Novel biomarkers for lung cancer diagnosis, prediction and treatment. Exp Biol Med (Maywood) 237: 227-235, 2012.

25. Bertoli G, Cava C and Castiglioni I: MicroRNAs: New biomarkers for diagnosis, prognosis, therapy prediction and therapeutic tools for breast cancer. Theranostics 5: 1122-1143, 2015.

26. Wang Z, Sha HH and Li HJ: Functions and mechanisms of miR-186 in human cancer. Biomed Pharmacother 119: 109428, 2019.

27. Zhu L, Deng H, Hu J, Huang S, Xiong J and Deng J: The promising role of miR-296 in human cancer. Pathol Res Pract 214: 1915-1922, 2018.

28. Iacona JR and Lutz CS: miR-146a-5p: Expression, regulation, and functions in cancer. Wiley Interdiscip Rev RNA 10: e1533, 2019.

29. Kanellopoulou C and Monticelli S: A role for microRNAs in the development of the immune system and in the pathogenesis of cancer. Semin Cancer Biol 18: 79-88, 2008.

30. Irmak-Yazicioglu MB: Mechanisms of MicroRNA deregulation and MicroRNA targets in gastric cancer. Oncol Res Treat 39: 136-139, 2016.

31. Yu T, Ma P, Wu D, Shu Y and Gao W: Functions and mechanisms of microRNA-31 in human cancers. Biomed Pharmacother 108: 1162-1169, 2018.

32. Yan X, Yu H, Liu Y, Hou J, Yang Q and Zhao Y: miR-27a-3p functions as a tumor suppressor and regulates non-small cell lung cancer cell proliferation via targeting HOXB8. Technol Cancer Res Treat 18: 1533033819861971, 2019.

33. Li JM, Zhou J, Xu Z, Huang HJ, Chen MJ and Ji JS: MicroRNA-27a-3p inhibits cell viability and migration through down-regulating DUSP16 in hepatocellular carcinoma. J Cell Biochem 119: 5143-5152, 2018.

34. Zhou L, Liang X, Zhang L, Yang L, Nagao N, Wu H, Liu C, Lin S, Cai G and Liu J: MiR-27a-3p functions as an oncogene in gastric cancer by targeting BTG2. Oncotarget 7: 51943-51954, 2016.

35. Liang J, Tang J, Shi H, Li H, Zhen T, Duan J, Kang L, Zhang F, Dong Y and Han A: miR-27a-3p targeting RXRalpha promotes colorectal cancer progression by activating Wnt/beta-catenin pathway. Oncotarget 8: 82991-83008, 2017.

36. Li E, Han K and Zhou X: microRNA-27a-3p down-regulation inhibits malignant biological behaviors of ovarian cancer by targeting BTG1. Open Med (Wars) 14: 577-585, 2019.

37. Wu XZ, Wang KP, Song HJ, Xia JH, Jiang Y and Wang YL: MiR-27a-3p promotes esophageal cancer cell proliferation via F-box and WD repeat domain-containing 7 (FBXW7) suppression. Int J Clin Exp Med 8: 15556-15562, 2015

38. Wang YL, Gong WG and Yuan QL: Effects of miR-27a upregulation on thyroid cancer cells migration, invasion, and angiogenesis. Genet Mol Res 15, 2016.

39. Livak KJ and Schmittgen TD: Analysis of relative gene expression data using real-time quantitative PCR and the 2(-Delta Delta C(T)) method. Methods 25: 402-408, 2001.

40. Maqbool R, Lone SN and U1 Hussain M: Post-transcriptional regulation of the tumor suppressor p53 by a novel miR-27a, with implications during hypoxia and tumorigenesis. Biochem J 473: 3597-3610, 2016. 
41. Li P, Zhang Q and Tang H: INPP1 up-regulation by miR-27a contributes to the growth, migration and invasion of human cervical cancer. J Cell Mol Med 23: 7709-7716, 2019.

42. Li L and Luo Z: Dysregulated miR-27a-3p promotes nasopharyngeal carcinoma cell proliferation and migration by targeting Mapk10. Oncol Rep 37: 2679-2687, 2017.

43. Tang H, Xu X, Xiao W, Liao Y, Xiao X, Li L, Li K, Jia X and Feng $\mathrm{H}$ : Silencing of microRNA-27a facilitates autophagy and apoptosis of melanoma cells through the activation of the SYK-dependent mTOR signaling pathway. J Cell Biochem 120: 13262-13274, 2019.

44. Shang D, Xie C, Hu J, Tan J, Yuan Y, Liu Z and Yang Z: Pancreatic cancer cell-derived exosomal microRNA-27a promotes angiogenesis of human microvascular endothelial cells in pancreatic cancer via BTG2. J Cell Mol Med 24: 588-604, 2020.

45. Nelson J, Bagnato A, Battistini B and Nisen P: The endothelin axis: Emerging role in cancer. Nat Rev Cancer 3: 110-116, 2003.

46. Chen LL, Zhu J, Schumacher J, Wei C, Ramdas L, Prieto VG, Jimenez A, Velasco MA, Tripp SR, Andtbacka RHI, et al: SCF-KIT signaling induces endothelin-3 synthesis and secretion: Thereby activates and regulates endothelin-B-receptor for generating temporally- and spatially-precise nitric oxide to modulate SCF- and or KIT-expressing cell functions. PLoS One 12: e0184154, 2017.

47. Alcendor DJ: Dysregulation of endothelin-1: Implications for health disparities in Alzheimer's disease. J Pers Med 10: 199, 2020.

48. Davenport AP, Hyndman KA, Dhaun N, Southan C, Kohan DE, Pollock JS, Pollock DM, Webb DJ and Maguire JJ: Endothelin. Pharmacol Rev 68: 357-418, 2016.
49. Aydin AF, Vural P, Doğru-Abbasoğlu S and Çil E: The endothelin 1 and endothelin receptor A gene polymorphisms increase the risk of developing papillary thyroid cancer. Mol Biol Rep 46: 199-205, 2019.

50. Kang BY, Park K, Kleinhenz JM, Murphy TC, Sutliff RL, Archer D and Hart CM: Peroxisome proliferator-activated receptor $\gamma$ regulates the V-Ets avian erythroblastosis virus E26 oncogene homolog 1/microRNA-27a axis to reduce endothelin-1 and endothelial dysfunction in the sickle cell mouse lung. Am J Respir Cell Mol Biol 56: 131-144, 2017.

51. Xie X, Li S, Zhu Y, Liu L, Pan Y, Wang J, Shi W, Song Y, Yang L, Gao L, et al: MicroRNA-27a/b mediates endothelin-1-induced PPAR $\gamma$ reduction and proliferation of pulmonary artery smooth muscle cells. Cell Tissue Res 369: 527-539, 2017.

52. Kang BY, Park KK, Green DE, Bijli KM, Searles CD, Sutliff RL and Hart CM: Hypoxia mediates mutual repression between microRNA-27a and PPAR $\gamma$ in the pulmonary vasculature. PLoS One 8: e79503, 2013.

53. Lin H, Ma Y, Wei Y and Shang H: Genome-wide analysis of aberrant gene expression and methylation profiles reveals susceptibility genes and underlying mechanism of cervical cancer. Eur J Obstet Gynecol Reprod Biol 207: 147-152, 2016.

(c) () $(9$ This work is licensed under a Creative Commons EY No No Attribution-NonCommercial-NoDerivatives 4.0 International (CC BY-NC-ND 4.0) License. 